\title{
Synthesis and Evaluation of Some New Aza-B-homocholestane Derivatives as Anticancer Agents
}

\section{Yanmin Huang ${ }^{1}$, Jianguo Cui ${ }^{1}{ }^{1 *}$, Sijing Chen ${ }^{1}$, Qifu Lin ${ }^{1}$, Huacan Song ${ }^{2}$, Chunfang Gan ${ }^{1}$, Bin $\mathrm{Su}^{3}$ and Aimin $\mathrm{Zhou}^{3}$}

1 Key Laboratory of Beibu Gulf Environment Change and Resources Utilization, College of Chemistry and Life Science, Guangxi Teachers Education University, Nanning 530001, China; E-Mails: huangyanmin828@163.com (Y.H.); huaxue37z@126.com (S.C.); linqifu335@163.com (Q.L.); ganchunfang2008@126.com (C.G.)

2 School of Chemistry and Chemical Engineering, Sun Yat-sen University, Guangzhou 510275, China; E-Mail: YjhXhc@mail.sysu.edu.cn

3 Clinical Chemistry Program, Department of Chemistry, SI 424, Cleveland State University, Cleveland, OH 44115, USA; E-Mails: b.su@csuohio.edu (B.S.); a.zhou@csuohio.edu (A.Z.)

* Author to whom correspondence should be addressed; E-Mail: cuijg1954@126.com; Tel.: +86-771-3908065; Fax: +86-771-3908308.

Received: 26 December 2013; in revised form: 24 February 2014 / Accepted: 26 February 2014 / Published: 25 March 2014

\begin{abstract}
Using analogues of some marine steroidal oximes as precursors, a series of aza- $B$-homocholestane derivatives possessing different substituted groups at the 3-position of the steroidal nucleus were synthesized. Their biological activity against cancer cell proliferation was determined with multiple cancer cell lines. Aza- $B$-homocholestane derivatives possessing 3-hydroxyl, 3-hydroximino and 3-thiosemicarbazone groups displayed remarkable cytotoxicity to cancer cells via apoptosis inducing mechanism. Compounds 5, 10, 12, 15 and 18 exhibited better potency to inhibit cancer cell proliferation. In addition, compound 15 was further evaluated with three dimensional (3D) multicellular spheroids assay to determine its potency against spheroid growth. The structure-activity relationship (SAR) generated in the studies is valuable for the design of novel chemotherapeutic agents.
\end{abstract}

Keywords: aza- $B$-homo-cholestane derivatives; anticancer agents; cytotoxicity; 3D multicellular spheroids screening; apoptosis 


\section{Introduction}

Natural products derived from marine organisms are important resources of biologically active compounds. Compounds with steroidal skeletons are abundant in marine sponges [1]. However, marine steroids having an oxime group have been less reported in the literatures. (6E)-Hydroximino-24-ethylcholest-4-en-3-one (1) and (6E)-hydroximinocholest-4-en-3-one (2) were two interesting steroidal compounds having 6-oxime group, and were isolated from the sponges Cinachyrella (C. alloclada and C. apion) (Figure 1) [2]. Compound 2 showed cytotoxicity with $\mathrm{IC}_{50}$ of $1.25 \mu \mathrm{g} / \mathrm{mL}$ against P-388, A-549, HT-29 cells, and $2.5 \mu \mathrm{g} / \mathrm{mL}$ toward MEL-28 cells. Based on the results, different types of steroidal oxime derivatives were synthesized and their cytotoxicities were evaluated [3-8].

Figure 1. Chemical structures of compounds 1 and 2.
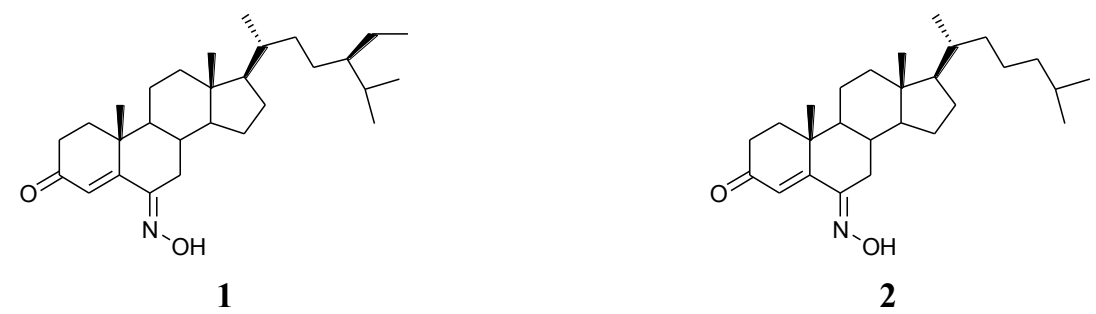

Aza-homosteroids are a class of steroid compounds that were synthesized and modified in order to increase the biological activity of the lead steroids. The synthesis of some aza-homosteroid compounds with unusual and interesting structures had been reported recently [9-14]. These compounds exhibited cytotoxic, antibacterial, antileukemic, and antiandrogenic activities. Studies of aza-homosteroids revealed that the presence of the characteristic group (-NH-CO-) in the aza-homosteroid molecule is important in lowering the acute toxicity and improving anticancer activity of the compounds $[15,16]$.

In our previous work, a series of 3-aza- $A$-homo and 4-aza- $A$-homo steroidal lactams were prepared and evaluated against the proliferation of SGC 7901 (human ventriculi carcinoma cell line), HeLa (human cervical carcinoma cell line) and Bel 7404 (human liver carcinoma cell line) [17-19]. The results showed that some of these steroidal lactams significantly inhibited the proliferation of the tumor cell lines tested and induced cancer cell apoptosis as well. In order to find more active derivatives as potential antitumor agents, a series of the new aza- $B$-homecholestane derivatives possessing different aza-position and various substitute groups on the 3-position of steroidal nucleus were designed and synthesized taking analogues of compound $\mathbf{2}$ as precursors. The antiproliferative activities of these new compounds were evaluated with different cancer cell lines.

\section{Results and Discussion}

\subsection{Chemistry}

First, 3-hydroximino-7-aza- $B$-homocholest-4-en-6-one (7) was synthesized as listed in Scheme 1. The synthesis of steroidal oxime (3) had been reported by our group [7]. Beckman rearrangement of 3 in $\mathrm{SOCl}_{2}$ /THF gave 3-acetoxy-7-aza- $B$-homocholest-4-en-6-one (4). The structure of 4 was confirmed by ${ }^{1} \mathrm{H}$ NMR chemical shifts of 7a-protons at 3.16-3.21 ppm $(2 \mathrm{H}, \mathrm{m})$. Compound 5 was obtained by 
deacetylation of 4 in aqueous solution of $13 \% \mathrm{~K}_{2} \mathrm{CO}_{3}$. The oxidation of compound 5 with Jones reagent afforded 7-aza- $B$-homocholest-4-en-3,6-dione (6). Last, the oxime 7 was produced in a yield of $42 \%$ by the reaction of 6 with hydroxylamine hydrochloride in ethanol in the presence of NaOAc. The structure of 7 was confirmed by analysis of the proton and carbon NMR chemical shifts. The downfield chemical shift of $2 \beta-\mathrm{H}$ at $3.453 \mathrm{ppm}$ (dd, $J=15.3$ and $4.8 \mathrm{~Hz}$, due to the deshielding influence of the $\mathrm{OH}$ in the hydroximino group) and C-3 at $158.6 \mathrm{ppm}$ demonstrated the (E)-configuration and formation of 3-hydroximino in compound 7.

Scheme 1. Synthesis of 3-hydroximino-7-aza- $B$-homocholest-4-en-6-one.
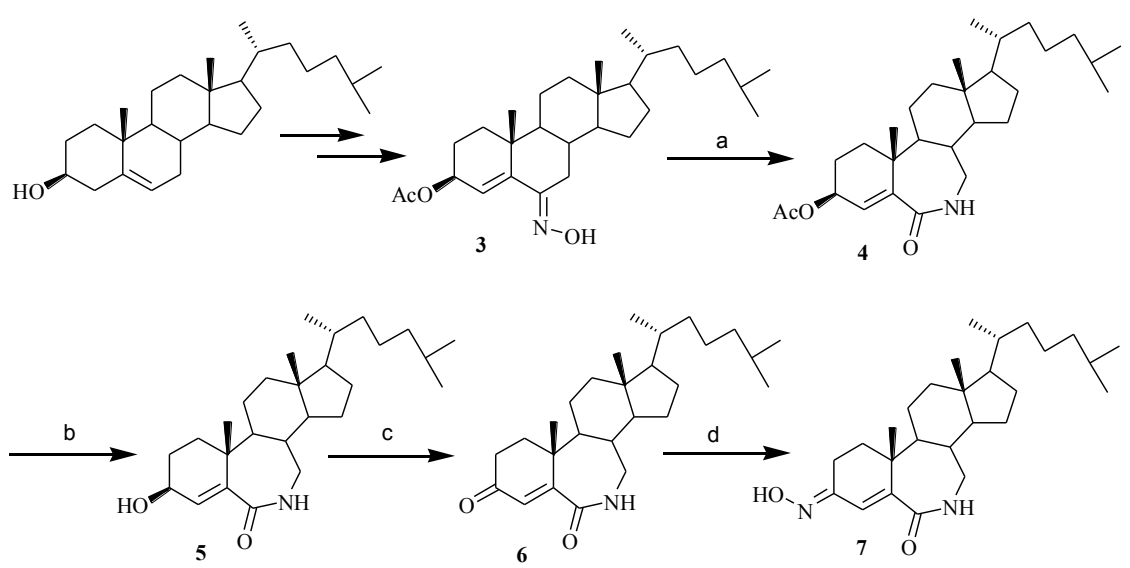

Reagents and conditions: (a) $\mathrm{SOCl}_{2} / \mathrm{THF}, 0{ }^{\circ} \mathrm{C}$; (b) $13 \% \quad \mathrm{~K}_{2} \mathrm{CO}_{3} / \mathrm{CH}_{3} \mathrm{OH}$, stirred, $4 \mathrm{~h}$; (c) Jones reagent/acetone, r. t., 2 h; (d) $\mathrm{H}_{2} \mathrm{NOH} . \mathrm{HCl} / \mathrm{Na}_{2} \mathrm{Ac} .3 \mathrm{H}_{2} \mathrm{O} / \mathrm{EtOH}$, reflux.

Scheme 2. Synthesis of compounds 9-15.
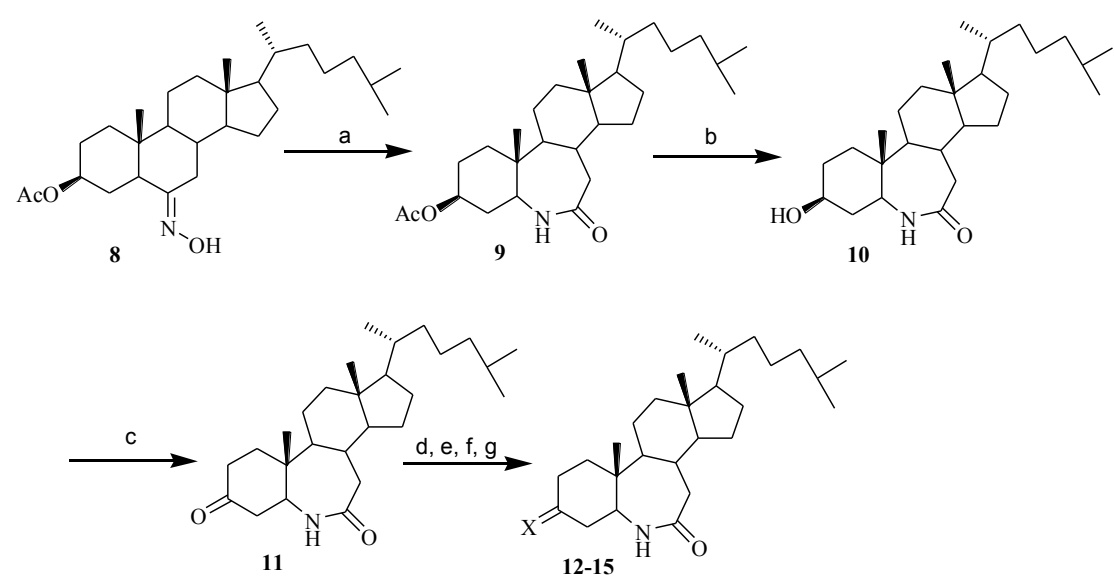

12: $\mathrm{X}=\mathrm{NOH} ;$ 13: $\mathrm{X}=\mathrm{NOCH}_{3} ;$ 14: $\mathrm{X}=\mathrm{NOCH}_{2} \mathrm{Ph} ;$ 15: $\mathrm{X}=\mathrm{NNHCSNH}_{2}$. Reagents and conditions: (a) $\mathrm{SOCl}_{2} / \mathrm{THF}, 0{ }^{\circ} \mathrm{C}$; (b) $13 \% \mathrm{~K}_{2} \mathrm{CO}_{3} / \mathrm{CH}_{3} \mathrm{OH}$, reflux, $4 \mathrm{~h}$; (c) Jones reagent/acetone, r. t., $2 \mathrm{~h}$; (d) $\mathrm{H}_{2} \mathrm{NOH} . \mathrm{HCl} / \mathrm{Na}_{2} \mathrm{Ac} .3 \mathrm{H}_{2} \mathrm{O} / \mathrm{EtOH}$, reflux; (e) $\mathrm{CH}_{3} \mathrm{ONH}_{2} \cdot \mathrm{HCl} / 95 \% \mathrm{C}_{2} \mathrm{H}_{5} \mathrm{OH}, 60{ }^{\circ} \mathrm{C}$; (f) $\mathrm{PhCH}_{2} \mathrm{ONH}_{2} / 95 \% \mathrm{C}_{2} \mathrm{H}_{5} \mathrm{OH}, 60{ }^{\circ} \mathrm{C}$; (g) $\mathrm{H}_{2} \mathrm{NC}(\mathrm{S}) \mathrm{NHNH}_{2} / \mathrm{EtOH}, 60{ }^{\circ} \mathrm{C}$.

Similarly, compounds 12-15 possessing the 3-substituted-6-aza- $B$-homocholest-7-one key feature in their structures were synthesized with 8 steps using cholesterol as starting material (Scheme 2). Compound 8 was synthesized based on the known methodology [8]. The structure of 9 was affirmed by proton and carbon NMR spectrums. In the ${ }^{1} \mathrm{H}$ NMR spectrum, the resonances showing of $\mathrm{C}_{5}-\alpha \mathrm{H}$ at 3.47-3.40 ppm $(1 \mathrm{H}, \mathrm{m}), \mathrm{C}_{7 \mathrm{a}}-\mathrm{H}$ at 2.36-2.22 ppm $(2 \mathrm{H}, \mathrm{m})$ and 7-C at $176.2 \mathrm{ppm}$ demonstrated a 
formation of NH-CO- bond and a position of 6-NH. The oxidization of $\mathbf{1 0}$ by Jones reagent generated compound 11. The reaction of compound 11 with $\mathrm{HONH}_{2} \cdot \mathrm{HCl}, \mathrm{CH}_{3} \mathrm{ONH}_{2} \cdot \mathrm{HCl}, \mathrm{PhCH}_{2} \mathrm{ONH}_{2} \cdot \mathrm{HCl}$ or thiosemicarbazide afforded the corresponding products 12-15. Their structures were confirmed by IR and NMR spectrum, and the mixture of $E$ - and $Z$-stereoisomer was obtained in preparation of 13-15, respectively.

Last, in order to determine if the aza-position has an effect on the compounds' cytotoxicity, compounds 17-21 possessing the structure of 7a-aza- $B$-homocholest-4(or 5)-ene were prepared (Scheme 3). Beckman rearrangement of $\mathbf{1 6}$ provided 3-acetoxy-7a-aza- $B$-homocholest-5-ene-7-one (17). The downfield chemical shift of $\mathrm{C}_{8}-\mathrm{H}$ at $3.292 \mathrm{ppm}(1 \mathrm{H}, \mathrm{t}, J=8.4)$ in ${ }^{1} \mathrm{H}$ NMR spectrum of 17 indicated the position of 7a-aza. In the oxidization of compound 18 by Jones reagent, 5,6-double bond of $\mathbf{1 8}$ was transformed into more stable 4,5-double bond of compound 19. Further, compounds $\mathbf{2 0}$ and 21 were obtained by the reaction of 19 with $\mathrm{HONH}_{2} \cdot \mathrm{HCl}$ and thiosemicarbazide respectively. The structures of 20, 21 were confirmed with proton and carbon NMR.

Scheme 3. Synthesis of compounds 17-21.
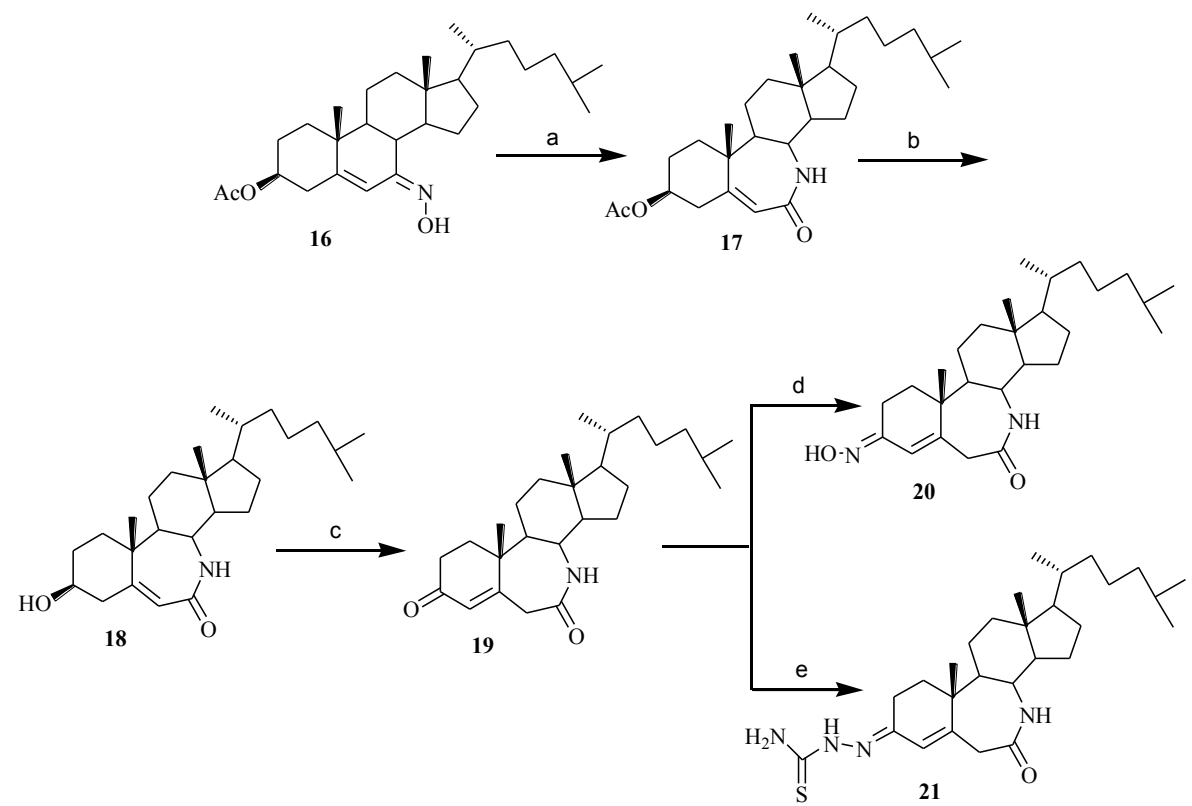

Reagents and conditions: (a) $\mathrm{SOCl}_{2} / \mathrm{THF}, 0{ }^{\circ} \mathrm{C}$; (b) $13 \% \mathrm{~K}_{2} \mathrm{CO}_{3} / \mathrm{CH}_{3} \mathrm{OH}$, reflux, $4 \mathrm{~h}$; (c) Jones reagent/acetone, r.t., 2 h; (d) $\mathrm{H}_{2} \mathrm{NOH} . \mathrm{HCl} / \mathrm{Na}_{2} \mathrm{Ac} .3 \mathrm{H}_{2} \mathrm{O} / \mathrm{EtOH}$, reflux; (e) $\mathrm{H}_{2} \mathrm{NC}(\mathrm{S}) \mathrm{NHNH}_{2} / \mathrm{EtOH}$, $60{ }^{\circ} \mathrm{C}$.

\subsection{Biological Evaluation}

\subsubsection{Cytotoxicity Determination}

All compounds were evaluated for their antiproliferative activities against SGC 7901 (human gastric carcinoma), HeLa (human cervical carcinoma), Bel 7404 (human liver carcinoma) GNE 2 (nasopharyngeal carcinoma), SPC-A (lung carcinoma) and Tu 686 (laryngocarcinoma) cell lines using the MTT assay. The results were summarized as $\mathrm{IC}_{50}$ values in $\mu \mathrm{M}$ in Table 1 . 
Table 1. In vitro ${ }^{\text {a }}$ antiproliferative activities of aza- $B$-homocholestane derivatives $\left(\mathrm{IC}_{50}\right.$ in $\left.\mu \mathrm{M}\right)$.

\begin{tabular}{ccccccc}
\hline Compounds & SGC 7901 & HeLa & Bel 7404 & GNE 2 & SPC-A & Tu 686 \\
\hline $\mathbf{4}$ & 91.8 & 20.8 & 14.2 & 34.5 & 92.5 & 85.4 \\
$\mathbf{5}$ & 13.2 & 26.5 & 9.8 & 7.2 & 7.5 & 25.4 \\
$\mathbf{6}$ & $>100$ & 31.4 & $>100$ & 29.2 & $>100$ & 58.6 \\
$\mathbf{7}$ & $>100$ & 9.3 & 58.4 & $>100$ & $>100$ & 98.5 \\
$\mathbf{8}$ & 25.0 & 52.1 & 17.4 & 34.8 & 15.6 & 59.8 \\
$\mathbf{9}$ & 66.3 & 8.3 & 15.4 & 15.2 & 98.5 & 58.4 \\
$\mathbf{1 0}$ & 31.8 & 3.2 & 11.6 & 9.5 & 47.6 & 42.5 \\
$\mathbf{1 1}$ & 90.4 & 8.7 & 8.7 & 16.1 & 74.5 & 6.8 \\
$\mathbf{1 2}$ & 92.4 & 9.1 & 31.3 & 11.3 & 34.8 & 28.5 \\
$\mathbf{1 3}$ & 70.5 & 35.8 & 69.8 & 63.8 & 78.7 & 36.0 \\
$\mathbf{1 4}$ & 26.5 & 22.9 & 37.8 & 5.4 & 34.0 & 23.6 \\
$\mathbf{1 5}$ & 29.5 & 5.5 & 9.8 & 12.4 & 6.6 & 28.9 \\
$\mathbf{1 6}$ & $>100$ & $>100$ & $>100$ & $>100$ & 48.5 & $>100$ \\
$\mathbf{1 7}$ & $>100$ & $>100$ & $>100$ & 17.5 & $>100$ & 36.2 \\
$\mathbf{1 8}$ & 11.3 & 6.0 & 4.8 & 20.1 & 23.4 & 25.3 \\
$\mathbf{2 0}$ & 25.7 & 35.7 & 42.2 & 43.0 & 35.6 & 42.5 \\
$\mathbf{2 1}$ & 24.6 & 16.4 & 45.2 & 39.0 & ND ${ }^{\mathrm{b}}$ & $\mathrm{ND}$ \\
Cisplatin & 6.7 & 10.1 & 23.2 & 16.8 & 15.2 & 17.5 \\
\hline
\end{tabular}

${ }^{\mathrm{a}}$ Data represent the mean values of three independent determinations; ${ }^{\mathrm{b}}$ Not determined.

As shown in Table 1, compounds 8-15 possessing the structure of 3-substituted-6-aza- $B$ homocholest-7-one had better antiproliferative activity than compounds 4-7 with the structure of 3 -substituted-7-aza- $B$-homocholest-4-ene-6-one and compounds 17, 18, 20, 21 with the structure of 3 -substituted-7a-aza- $B$-homocholest-4(or 5)-ene-7-one. Compound 5 with 3-hydroxyl group exhibited better antiproliferative activity than the compound 4 with 3-acetoxyl, the 6 with 3-carbonyl and the 7 with 3-hydroximino groups. Comparing to analogues 8-15, compounds 10, 12, 15 possessing 3-hydroxyl, 3-hydroximino and 3-thiosemicarbazone groups displayed better cytotoxicity. Moreover, compound 18 with 3-hydroxyl group showed the best antiproliferative activity in analogues 17, 18 and 20, 21.

Interestingly, all compounds with 3-hydroxyl, hydroximino and thiosemicarbazone groups exhibited a higher cytotoxicity against HeLa cells. For example, compound $\mathbf{1 0}$ with 3-hydroxyl and compound 15 with 3-thiosemicarbazone exhibited $\mathrm{IC}_{50}$ values of 3.2 and $5.5 \mu \mathrm{M}$ to $\mathrm{HeLa}$ cells, respectively. Apparently, all compounds $(\mathbf{5}, \mathbf{1 0}, \mathbf{1 8})$ bearing the same 3-hydroxyl and a different aza-position displayed a similar cytotoxicity against these cancer cells. However, compound $\mathbf{1 5}$ having same 3-thiosemicarbazone and 6-aza- $B$-homocholest-7-one key features in its structure showed a better antiproliferative activity to these cancer cells than compound $\mathbf{2 1}$ with the structure of 7a-aza- $B$-homocholest-5-ene-7-one except SGC 7901 cell.

Above results showed that the conversion of a carbonyl group at 3-position to a hydroxyl, hydroximino, or thiosemicarbazone groups would result in a significant increase of the antiproliferative activity, suggesting the importance of these functional groups in the biological 
function of the compounds. Obviously, the substitution of the 3-hydroxyl group remarkably increased its cytotoxic activity against these cancer cells in comparison with the 3-acetoxyl group.

Overall, compounds 5, 10, 12, 15 and 18 were found to be the most potent compounds as anticancer agents, and they displayed a similar antiproliferative activity, when compared to cisplatin (a positive control).

\subsubsection{D Multicellular Spheroids Screening}

Screening and initial characterization of anticancer drugs typically use monolayer cultures of tumor cells. However, such monolayer cultures do not represent the characteristics of threedimensional (3D) solid tumors. The multicellular tumor spheroid model has an intermediate complexity between in vivo tumors and in vitro monolayer cell cultures. Considering the complexity of the in vivo situation, it is not surprising that many drugs that are effective in a twodimensional cell culture will lose efficacy with the in vivo assays. Limited penetration of the drug into tumor cell masses is one main factor that will lead to poor drug efficacy in animal models. Testing the efficacy of the drug with tumor spheroids may help to predict their in vivo potency [20]. Herein, compound 15 was examined with the 3D spheroid growth assay.

Spheroids were photographed in an inverted phase contrast microscope. A micrometer scale was photographed at the same magnification, and spheroid size was determined and compared.

In Figure 2, the spheroids treated with $15 \mu \mathrm{M}$ of $\mathbf{1 5}$ had a smaller size after 6 days than the untreated control spheroids. The result indicated that compound 15 showed good tumor penetration ability.

Figure 2. Time-lapse images of control untreated 5000-cell H-292 spheroid, and spheroid treated with $20 \mu \mathrm{M}$ 15. Scale bar is $100 \mu \mathrm{m}$.

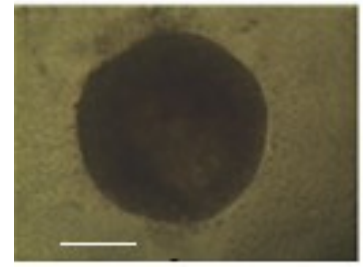

Day $2(0 \mathrm{~h})$, untreated

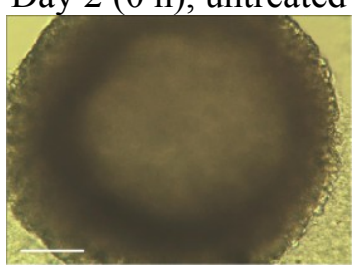

Day 7 (120 h), untreated

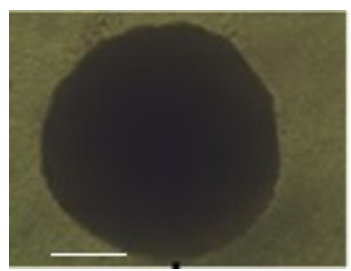

Day 4 (48 h), untreated

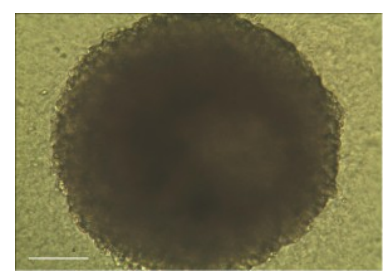

Day 5 (72 h), untreated

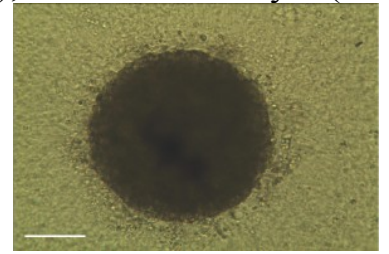

Day 7 (120 h), $15 \mu \mathrm{M} 15$

\subsubsection{Compound 5 Induced Apoptosis of Cancer Cells}

To determine the molecular mechanism by which compound $\mathbf{5}$ inhibited cancer cell proliferation, we further analyzed the cytotoxicity of compound 5 in SGC-7901 cells. As shown in Figure 3, compound 5-induced SGC-7901 cell death could be clearly observed. 
Figure 3. Photographs of the unstained cells were taken under Olympus model CKX31 at 100 magnification after treatment of MGC 7901 cells with various doses of compound $\mathbf{5}$ for $48 \mathrm{~h}$.

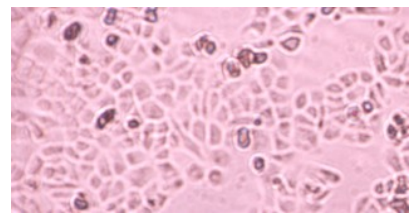

Control

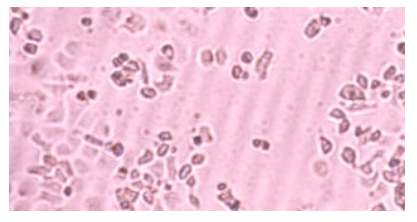

$2.5 \mu \mathrm{g} / \mathrm{mL}$

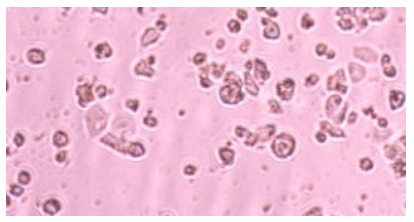

$5 \mu \mathrm{g} / \mathrm{mL}$

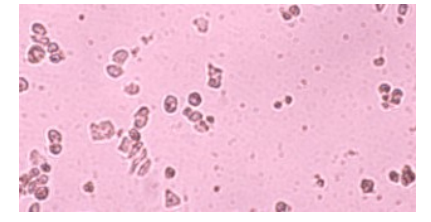

$10 \mu \mathrm{g} / \mathrm{mL}$

To determine whether the decreased viability of SGC-7901 cells was due to compound $\mathbf{5}$ induced apoptosis, the cells were treated with compound 5, and Annexin V assay was performed. FITC-conjugated Annexin V is commonly used to determine apoptotic cells at an early stage. As shown in Figure 4, treatment with $5 \mu \mathrm{g} / \mathrm{mL}$ of compound 5 resulted in $8.12 \% \mathrm{PI} /$ Annexin $\mathrm{V}$ double-labeled apoptotic cells (control: 0.57\%; cisplatinum: 8.94\%) after $24 \mathrm{~h}$ incubation (the lower right quadrant and the upper right quadrant which contains early and late apoptotic cells, respectively), suggesting compound $\mathbf{5}$ is a potent apoptotic inducer in gastric carcinoma cells.

Figure 4. SGC-7901 cells were double-stained with annexin V/PI and analyzed by flow cytometry. Treatment with compound $5(5 \mu \mathrm{g} / \mathrm{mL})$ and cisplatinum $(10 \mu \mathrm{g} / \mathrm{mL})$ for $24 \mathrm{~h}$ induced apoptosis of SGC-7901 cells.

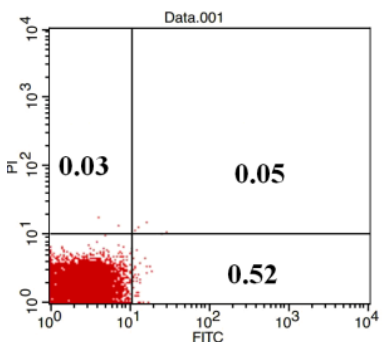

$24 \mathrm{~h}$ (Control)

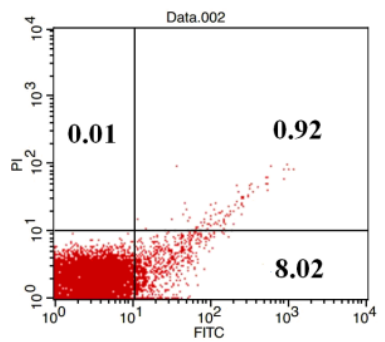

24 h (cisplatinum)

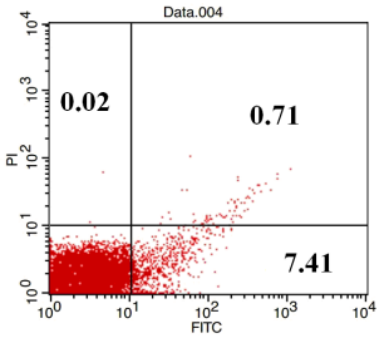

$24 \mathrm{~h}$ (compound 5)

The similar result was observed after treating with compound $\mathbf{5}$ in a dose dependent manner (Figure 5). Treatment with $5 \mu \mathrm{g} / \mathrm{mL}, 10 \mu \mathrm{g} / \mathrm{mL}, 15 \mu \mathrm{g} / \mathrm{mL}$ of compound 5 for $48 \mathrm{~h}$ resulted in 17.98, 30.21, 87.15\% PI/Annexin V double-labeled apoptotic cells, proposing compound $\mathbf{5}$ induced the apoptosis of SGC-7901 cells further.

Figure 5. Dose depended apoptosis induced by compound 5 and cisplatinum $(10 \mu \mathrm{g} / \mathrm{mL})$ for $48 \mathrm{~h}$.

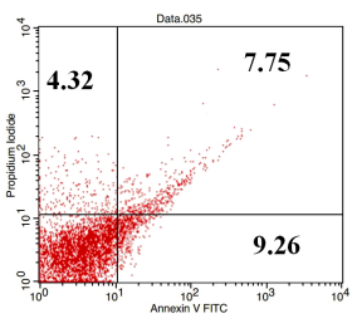

Cisplatinum(10 $\mu \mathrm{g} / \mathrm{mL})$

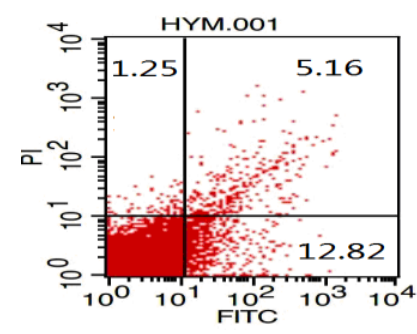

$5 \mu \mathrm{g} / \mathrm{mL}$

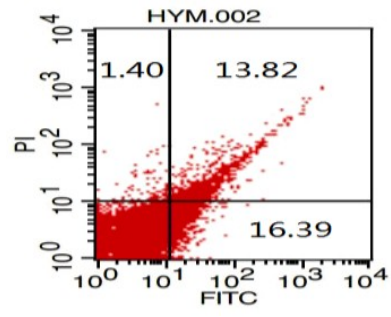

$10 \mu \mathrm{g} / \mathrm{mL}$

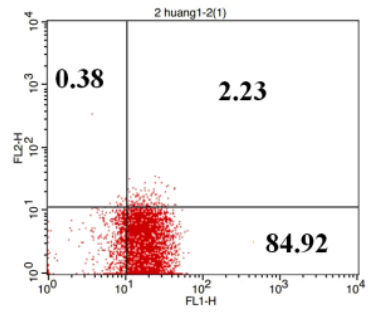

$15 \mu \mathrm{g} / \mathrm{mL}$ 


\section{Experimental Section}

\subsection{Chemistry}

The sterols were purchased from the Sinopharm Chemical Reagent Co., Ltd., Shanghai, China. All chemicals and solvents were analytical grade and solvents were purified by general methods before being used. Melting points were determined on an X4 apparatus and were uncorrected. Infrared spectra were measured with a Nicolet FT-360 Spectrophotometer (Thermo Fisher Scientific, New York, NY, USA). The ${ }^{1} \mathrm{H}$ and ${ }^{13} \mathrm{C}$ NMR spectra were recorded in $\mathrm{CDCl}_{3}$ on a Bruker $\mathrm{AV}-600$ spectrometer (Bruker Corporation, Billerica, MA, USA) at working frequencies 600 and $150 \mathrm{MHz}$, and a Bruker AV-300 spectrometer at working frequencies 300 and $75 \mathrm{MHz}$, respectively. Chemical shifts are expressed in parts per million $(\delta)$ values and coupling constants $(J)$ in Hertz. LREIMS were recorded on a Thermo-DSQ instrument (Thermo Fisher Scientific, New York, NY, USA), while HREIMS were measured on a Agilent 6210 TOFMS instrument (Agilent Technologies, Palo Alto, CA, USA). The cell proliferation assay was undertaken by a MTT method using 96-well plates on MLLTISKAN MK3 analysis spectrometer (Thermo Scientific, Shanghai, China). Annexin V assay was performed using FACS Calibur flow cytometry (Becton Dickinson, Biosciences, Franklin Lakes, NJ, USA).

Compounds 3, 16 were prepared according to the procedures in the literature [7].

\subsubsection{3-Acetoxy-7-aza- $B$-homocholest-4-ene-6-one (4)}

The solution of thionyl chloride $(1.5 \mathrm{~mL})$ in $5 \mathrm{~mL}$ dry THF was added to a solution of the oxime 3 (300 mg) in dry THF $(30 \mathrm{~mL})$. The solution was stirred under anhydrous condition for $1 \mathrm{~h}$ at $0{ }^{\circ} \mathrm{C}$. The reaction was terminated and water was added to the solution. The solution was neutralized with ammonia and the product was extracted with $\mathrm{CH}_{2} \mathrm{Cl}_{2}(20 \times 3 \mathrm{~mL})$. The combined extract was washed with water, $5 \% \mathrm{NaHCO}_{3}$, and saturated brine, dried over anhydrous $\mathrm{Na}_{2} \mathrm{SO}_{4}$ and evaporated under reduced pressure to give a crude product which was chromatographed on silica gel (elution: Dichloromethane/methanol $=20 / 1)$ to give white solid $216 \mathrm{mg}$. Yield: $72 \%, \mathrm{mp} 157-159{ }^{\circ} \mathrm{C}$; IR $(\mathrm{KBr})$ v: $3195,2938,1740,1659,1470,1377,1230,1136,1230,1058 \mathrm{~cm}^{-1} ;{ }^{1} \mathrm{H} \mathrm{NMR}\left(\mathrm{CDCl}_{3}, 300 \mathrm{MHz}\right)$ $\delta: 0.70\left(3 \mathrm{H}, \mathrm{s}, 18-\mathrm{CH}_{3}\right), 0.86\left(3 \mathrm{H}, \mathrm{d}, J=6.6,26-\right.$ or $\left.27-\mathrm{CH}_{3}\right), 0.88\left(3 \mathrm{H}, \mathrm{d}, J=6.6,26-\right.$ or $\left.27-\mathrm{CH}_{3}\right), 0.91$ $\left(3 \mathrm{H}, \mathrm{d}, J=6.6,21-\mathrm{CH}_{3}\right), 1.21\left(3 \mathrm{H}, \mathrm{s}, 19-\mathrm{CH}_{3}\right), 2.14\left(3 \mathrm{H}, \mathrm{s},-\mathrm{OCOCH}_{3}\right), 3.16-3.21(2 \mathrm{H}, \mathrm{m}, \mathrm{C} 7 \mathrm{a}-\mathrm{H}), 5.53$ $\left(1 \mathrm{H}, \mathrm{dd}, J=12.3,4.5, \mathrm{C}_{3}-\alpha \mathrm{H}\right), 5.91\left(1 \mathrm{H}, \mathrm{s}, \mathrm{C}_{4}-\mathrm{H}\right), 6.72(1 \mathrm{H}, \mathrm{s}, 6-\mathrm{NH}) ;{ }^{13} \mathrm{C} \mathrm{NMR}\left(\mathrm{CDCl}_{3}, 75 \mathrm{MHz}\right) \delta$ : 169.9 (6-C), $169.8\left(\mathrm{COCH}_{3}\right), 156.7$ (5-C), 114.7 (4-C), 71.2 (3-C), 56.0 (17-C), 55.5 (14-C), 53.3 (9-C), 45.5 (7a-C), 42.9 (13-C), 42.6 (24-C), 39.6 (12-C), 39.5 (8-C), 36.6 (10-C), 36.1 (22-C), 35.7 (20-C), 34.6 (1-C), 28.1 (16-C), 28.0 (25-C), 24.1 (15-C), 23.8 (2-C), 22.8 (26 or 27-C), 22.5 (26 or 27-C), 21.8 (23-C), 21.4 (11-C), 21.3 ( $\left.\mathrm{CH}_{3} \mathrm{CO}\right), 20.8$ (19-C), 18.6 (21-C), 12.0 (18-C); $\operatorname{LRESI-MS}(\mathrm{m} / \mathrm{z}): 458.3[\mathrm{M}+\mathrm{H}]^{+}$(Supplementary Information: Figure S1).

\subsubsection{3-Hydroxy-7-aza- $B$-homocholest-4-ene-6-one (5)}

$20 \mathrm{~mL}$ of $\mathrm{K}_{2} \mathrm{CO}_{3}$ solution (13\%) was added to a solution of compound 4 (1520 $\mathrm{mg}, 3.32 \mathrm{mmol}$ ) in $\mathrm{CH}_{3} \mathrm{OH}(200 \mathrm{~mL})$. The reaction mixture was heated under reflux condition for $1 \mathrm{~h}$. After completion of the reaction as indicated by TLC, the solvent was removed under reduced pressure. $200 \mathrm{~mL}$ of $\mathrm{CH}_{2} \mathrm{Cl}_{2}$ 
was added to dissolve solid and the resulting solution was washed with cold water and saturated brine. After drying over anhydrous sodium sulfate, the solvent was removed under reduced pressure, and the resulting crude product was purified by chromatography on silica gel using methanol/dichloromethane (30:1) as elution to give $988 \mathrm{mg}$ of 5 as white solid. Yield: $65 \%, \mathrm{mp} 233-234{ }^{\circ} \mathrm{C}$; IR (KBr) v: 3366 , 2941, 2872, 1654, 1593, 1470, 1380, 1319, 1123, $898 \mathrm{~cm}^{-1} ;{ }^{1} \mathrm{H}$ NMR $\left(\mathrm{CDCl}_{3}, 600 \mathrm{MHz}\right) \delta: 0.71(3 \mathrm{H}$, s, $\left.18-\mathrm{CH}_{3}\right), 0.88\left(3 \mathrm{H}, \mathrm{d}, J=6.6,26-\right.$ or $\left.27-\mathrm{CH}_{3}\right), 0.89\left(3 \mathrm{H}, \mathrm{d}, J=6.6,26-\right.$ or $\left.27-\mathrm{CH}_{3}\right), 0.92(3 \mathrm{H}, \mathrm{d}$, $\left.J=6.6,21-\mathrm{CH}_{3}\right), 1.15\left(3 \mathrm{H}, \mathrm{s}, 19-\mathrm{CH}_{3}\right), 2.16-2.20\left(1 \mathrm{H}, \mathrm{m}, \mathrm{C}_{2}-\mathrm{H}\right), 2.23(1 \mathrm{H}, \mathrm{br} \mathrm{s},-\mathrm{OH}), 3.16-3.21(1 \mathrm{H}$, $\left.\mathrm{m}, \mathrm{C}_{7 \mathrm{a}}-\alpha \mathrm{H}\right), 3.28-3.23\left(1 \mathrm{H}, \mathrm{m}, \mathrm{C}_{7 \mathrm{a}}-\beta \mathrm{H}\right), 4.43\left(1 \mathrm{H}, \mathrm{t}, J=5.4, \mathrm{C}_{3}-\alpha \mathrm{H}\right), 6.21\left(1 \mathrm{H}, \mathrm{s}, \mathrm{C}_{4}-\mathrm{H}\right), 6.38(1 \mathrm{H}, \mathrm{s}$, 7-NH); ${ }^{13} \mathrm{C} \mathrm{NMR}\left(\mathrm{CDCl}_{3}, 75 \mathrm{MHz}\right) \delta: 170.7$ (6-C), 162.1 (5-C), 114.3 (4-C), 69.6 (3-C), 56.0 (17-C), 55.6 (14-C), 53.1 (9-C), 45.0 (7a-C), 42.7 (13-C), 42.6 (12-C), 39.6 (24-C), 39.5 (8-C), 36.7 (10-C), 36.1 (22-C), 35.7 (20-C), 34.7 (1-C), 28.2 (2-C), 28.1 (16-C), 28.0 (25-C), 24.2 (15-C), 23.8 (23-C), 22.8 (26 or 27-C), 22.6 (26 or 27-C), 21.8 (11-C), 21.7 (19-C), 18.6 (21-C), 12.0 (18-C); HRESI-MS $(\mathrm{m} / z)$ : $416.3515[\mathrm{M}+\mathrm{H}]^{+}$(calcd for $\mathrm{C}_{27} \mathrm{H}_{46} \mathrm{NO}_{2}$, 416.3529) (Supplementary Information: Figure S2).

\subsubsection{7-Aza- $B$-homocholest-4-ene-3,6-dione (6)}

Jones reagent was added dropwise to the solution of $5(1 \mathrm{mmol})$ in $20 \mathrm{~mL}$ of acetone in $10 \mathrm{~min}$ at room temperature until the reaction solution didn't fade. The mixture was stirred at room temperature for $1 \mathrm{~h}$, and then neutralized with $10 \% \mathrm{~K}_{2} \mathrm{CO}_{3}$ solution. The suspension was poured over a silica gel column and eluted with ethyl acetate. The solvent was removed under reduced pressure. The residue was purified by chromatography on silica gel using methanol/dichloromethane (30:1) as elution to give $270 \mathrm{mg}$ of 6 as white solid. Yield: $65 \%$, mp $209-210{ }^{\circ} \mathrm{C}$. IR (KBr) v: 3509, 2933, 2868, 1695, 1658, $1605,1462,1376,1249,1074 \mathrm{~cm}^{-1} ;{ }^{1} \mathrm{H} \mathrm{NMR}\left(\mathrm{CDCl}_{3}, 600 \mathrm{MHz}\right) \delta: 0.72\left(3 \mathrm{H}, \mathrm{s}, 18-\mathrm{CH}_{3}\right), 0.88(3 \mathrm{H}, \mathrm{d}$, $J=6.6,26-\mathrm{CH}_{3}$ or $\left.27-\mathrm{CH}_{3}\right), 0.89\left(3 \mathrm{H}, \mathrm{d}, J=6.6,26\right.$ or $\left.27-\mathrm{CH}_{3}\right), 0.93\left(3 \mathrm{H}, \mathrm{d}, J=6.6,21-\mathrm{CH}_{3}\right), 1.06$ $\left(3 \mathrm{H}, \mathrm{s}, 19-\mathrm{CH}_{3}\right), 2.11-2.03\left(2 \mathrm{H}, \mathrm{m}, \mathrm{C}_{2}-\mathrm{H}\right.$ and $\left.\mathrm{C}_{1}-\mathrm{H}\right), 2.62\left(1 \mathrm{H}, \mathrm{dd}, J=15,4.5, \mathrm{C}_{2}-\mathrm{H}\right), 3.25-3.21(1 \mathrm{H}$, $\left.\mathrm{m}, \mathrm{C}_{7 \mathrm{a}}-\alpha \mathrm{H}\right), 3.35-3.30\left(1 \mathrm{H}, \mathrm{m}, \mathrm{C}_{7 \mathrm{a}}-\mathrm{\beta H}\right), 6.00\left(1 \mathrm{H}, \mathrm{s}, \mathrm{C}_{4}-\mathrm{H}\right), 6.43(1 \mathrm{H}, \mathrm{s},-\mathrm{NH}) ;{ }^{13} \mathrm{C} \mathrm{NMR}(75 \mathrm{MHz}$, $\left.\mathrm{CDCl}_{3}\right) \delta: 205.3$ (3-C), 168.7 (6-C), 156.8 (5-C), 121.5 (4-C), 56.4 (17-C), 55.9 (14-C), 51.2 (9-C), 47.1(13-C), 45.9(7a-C), 42.7 (12-C), 40.4 (24-C), 39.5 (8-C), 39.3 (10-C), 36.9(22-C), 36.0 (20-C), 35.7 (1-C), 35.3 (2-C), 28.0 (16-C), 28.0 (25-C), 23.9 (15-C), 23.8 (23-C), 22.8 (26 or 27-C), 22.5 (26-C or 27-C), 21.9 (11-C), 20.5 (19-C), 18.6 (21-C), 12.0 (18-C); HRESI-MS (m/z): 414.3362 $[\mathrm{M}+\mathrm{H}]^{+}$(calcd for $\mathrm{C}_{27} \mathrm{H}_{44} \mathrm{NO}_{2}, 414.3372$ ) (Supplementary Information: Figure S3).

\subsubsection{3-Hydroximino-7-aza- $B$-homocholest-4-ene-6-one (7)}

$\mathrm{CH}_{3} \mathrm{COONa} .3 \mathrm{H}_{2} \mathrm{O}(120 \mathrm{mg}, 0.33 \mathrm{mmol})$ and $\mathrm{NH}_{2} \mathrm{OH} . \mathrm{HCl}(23 \mathrm{mg}, 0.33 \mathrm{mmol})$ were added to the solution of $120 \mathrm{mg}(0.27 \mathrm{mmol}) 6$ in $20 \mathrm{~mL} \mathrm{95 \%} \mathrm{ethanol.} \mathrm{After} \mathrm{the} \mathrm{solution} \mathrm{was} \mathrm{heated} \mathrm{to} 60{ }^{\circ} \mathrm{C}$, the mixture was stirred at the temperature for $1 \mathrm{~h}$. Then the reaction was terminated and the majority of solvent was evaporated under reduced pressure. Water was added into the reaction mixture, and the product was extracted with ethyl acetate $(20 \times 3 \mathrm{~mL})$. The combined extracts were washed with saturated brine, dried, and evaporated under reduced pressure. The residue was subjected to chromatography using petroleum ether/ethyl acetate (5:1) as the eluent to give $50 \mathrm{mg}$ of 7 as white solid. Yield: $42 \%, \mathrm{mp} 285-286{ }^{\circ} \mathrm{C}$. IR (KBr) v: 3317, 2941, 2859, 2348, 1645, 1600, 1449, 1367 , 
1257, 963, $930 \mathrm{~cm}^{-1} ;{ }^{1} \mathrm{H}$ NMR $\left(\mathrm{d}_{6}-\mathrm{DMSO}, 600 \mathrm{MHz}\right) \delta: 0.70\left(3 \mathrm{H}, \mathrm{s}, 18-\mathrm{CH}_{3}\right), 0.88(3 \mathrm{H}, \mathrm{d}, J=6.6$, 26- or $\left.27-\mathrm{CH}_{3}\right), 0.89\left(3 \mathrm{H}, \mathrm{d}, J=6.6,26-\right.$ or $\left.27-\mathrm{CH}_{3}\right), 0.92\left(3 \mathrm{H}, \mathrm{d}, J=6.6,21-\mathrm{CH}_{3}\right), 1.08(3 \mathrm{H}, \mathrm{s}$, 19- $\left.\mathrm{CH}_{3}\right), 2.07-1.99(2 \mathrm{H}, \mathrm{m}$,$\left.) , 3.21-3.16 (1H, m, C \mathrm{7a}_{\mathrm{a}}-\alpha \mathrm{H}\right), 3.38-3.33\left(1 \mathrm{H}, \mathrm{m}, \mathrm{C}_{7 \mathrm{a}}-\beta \mathrm{H}\right), 3.45(1 \mathrm{H}, \mathrm{dd}$, $\left.J=15.3,4.8, \mathrm{C}_{2}-\beta \mathrm{H}\right), 6.11\left(1 \mathrm{H}, \mathrm{d}, J=1.8, \mathrm{C}_{4}-\mathrm{H}\right), 6.33(1 \mathrm{H}, \mathrm{s},-\mathrm{NH}), 9.50(\mathrm{H}, \mathrm{s},=\mathrm{N}-\mathrm{OH}) ;{ }^{13} \mathrm{C}$ NMR $\left(\mathrm{d}_{6}\right.$-DMSO, 75MHz) $\delta$ : 168.0 (6-C), 158.6 (3-C), 153.3 (5-C), 121.3 (4-C), 56.1 (17-C), 55.9 (14-C), 51.2 (9-C), 44.8 (7a-C), 42.6 (13-C), 36.0 (10-C), 35.5 (22-C), 33.9 (20-C), 30.4 (1-C), 28.2 (2-C), 27.8 (16-C), 27.8 (25-C), 23.6 (15-C), 23.1 (23-C), 22.9 (26 or 27-C), 21.8 (11-C), 20.7 (19-C), 18.9 (21-C), 12.2 (18-C); HRESI-MS $(\mathrm{m} / \mathrm{z}): 429.3463[\mathrm{M}+\mathrm{H}]^{+}$(calcd for $\mathrm{C}_{27} \mathrm{H}_{45} \mathrm{~N}_{2} \mathrm{O}_{2}, 429.3481$ ) (Supplementary Information: Figure S4).

Compounds in Scheme 2 were prepared similarly according to the procedure of Scheme 1.

\subsubsection{The Synthesis of 3-Acetoxy-6-aza-B-homocholest-7-one (9)}

White solid, yield 93\%, mp 222-223 ${ }^{\circ} \mathrm{C}$; IR(KBr) v: 3346, 2974, 2945, 2864, 1719, 1662, 1654 , 1474, 1364, $1249 \mathrm{~cm}^{-1} ;{ }^{1} \mathrm{H}$ NMR( $\left(\mathrm{CDCl}_{3}, 300 \mathrm{MHz}\right) \delta: 0.68\left(3 \mathrm{H}, \mathrm{s}, 18-\mathrm{CH}_{3}\right), 0.86\left(3 \mathrm{H}, \mathrm{s}, 19-\mathrm{CH}_{3}\right), 0.87$ $\left(6 \mathrm{H}, \mathrm{d}, J=6.3,26-\right.$ and $\left.27-\mathrm{CH}_{3}\right), 0.90\left(3 \mathrm{H}, \mathrm{d}, J=6.3,21-\mathrm{CH}_{3}\right), 2.05\left(3 \mathrm{H}, \mathrm{s}, \mathrm{CH}_{3} \mathrm{CO}-\right), 2.36-2.22(2 \mathrm{H}$, $\left.\mathrm{m}, \mathrm{C}_{7 \mathrm{a}}-\mathrm{H}\right), 3.47-3.40\left(1 \mathrm{H}, \mathrm{m}, \mathrm{C}_{5}-\mathrm{H}\right), 4.70-4.60\left(1 \mathrm{H}, \mathrm{m}, \mathrm{C}_{3}-\alpha \mathrm{H}\right), 5.54(1 \mathrm{H}, \mathrm{d}, J=5.1, \mathrm{~N}-\mathrm{H}) ;{ }^{13} \mathrm{C} \mathrm{NMR}$ $\left(\mathrm{CDCl}_{3}, 75 \mathrm{MHz}\right) \delta: 176.2(-\mathrm{CONH}), 170.5\left(\mathrm{COCH}_{3}\right), 70.9$ (3-C), 58.7 (14-C), 56.7 (17-C), 56.4 (5-C), 55.6 (9-C), 42.5 (7a-C), 40.2 (13-C), 39.9 (12-C), 39.5 (24-C), 38.7 (20-C), 35.9 (10-C), 35.7 (22-C), 35.3 (1-C), 34.6 (4-C), 34.5 (8-C), 28.0 (16-C), 27.6 (25-C), 27.0 (2-C), 25.6 (23-C), 23.8 (15-C), 23.0 (11-C), 22.8 (27-C), 22.6 (C-26), 21.3 ( $\mathrm{CH}_{3} \mathrm{CO}$ ), 18.6 (21-C), 12.4 (19-C), 11.8 (18-C); HRESI-MS $(\mathrm{m} / \mathrm{z}): 460.3784[\mathrm{M}+\mathrm{H}]^{+}$(calcd for $\left.\mathrm{C}_{29} \mathrm{H}_{50} \mathrm{NO}_{3}, 460.3791\right)$ (Supplementary Information: Figure S5).

\subsubsection{The Synthesis of 3-Hydroxy-6-aza- $B$-homocholest-7-one (10)}

White solid, yield: $76 \%$. mp $234-235{ }^{\circ} \mathrm{C}$. IR (KBr) v: 3321, 2953, 2864, 1650, 1446, 1384, $1053 \mathrm{~cm}^{-1} ;{ }^{1} \mathrm{H} \mathrm{NMR}\left(\mathrm{CDCl}_{3}, 600 \mathrm{MHz}\right) \delta: 0.67\left(3 \mathrm{H}, \mathrm{s}, 18-\mathrm{CH}_{3}\right), 0.84\left(3 \mathrm{H}, \mathrm{s}, 19-\mathrm{CH}_{3}\right), 0.85(3 \mathrm{H}, \mathrm{d}$, $J=6.6,26$ or $\left.27-\mathrm{CH}_{3}\right), 0.86\left(3 \mathrm{H}, \mathrm{d}, J=6.6,26\right.$ or $\left.27-\mathrm{CH}_{3}\right), 0.88\left(3 \mathrm{H}, \mathrm{d}, J=6.6,21-\mathrm{CH}_{3}\right), 2.24(1 \mathrm{H}$, t, $\left.J=13.8, \mathrm{C}_{7 \mathrm{a}}-\mathrm{H}\right), 2.33\left(1 \mathrm{H}, \mathrm{d}, J=13.8, \mathrm{C}_{7 \mathrm{a}}-\mathrm{H}\right), 3.38-3.34\left(1 \mathrm{H}, \mathrm{m}, \mathrm{C}_{5}-\mathrm{H}\right), 3.61-3.57\left(1 \mathrm{H}, \mathrm{m}, \mathrm{C}_{3}-\mathrm{H}\right), 5.30$ $(1 \mathrm{H}, \mathrm{s}, \mathrm{N}-\mathrm{H}) ;{ }^{13} \mathrm{C} \mathrm{NMR}\left(\mathrm{CDCl}_{3}, 75 \mathrm{MHz}\right) \delta: 176.3$ (7-C), 68.8 (3-C), 58.8 (14-C), 56.9 (17-C), 56.5 (5-C), 55.7 (9-C), 42.5 (7a-C), 40.3 (13-C), 39.9 (12-C), 39.5 (24-C), 38.6 (4-C), 36.0 (10-C), 35.7 (22-C), 35.6 (20-C), 34.6 (1-C), 30.9 (8-C), 28.0 (2-C), 28.0 (25-C), 27.6 (16-C), 25.6 (23-C), 23.8 (15-C), 23.0 (11-C), 22.8 (27-C), 22.6 (26-C), 18.6 (21-C), 12.5 (19-C), 11.8 (18-C); LRESI-MS (m/z): $418.3[\mathrm{M}+\mathrm{H}]^{+}$(Supplementary Information: Figure S6).

\subsubsection{The Synthesis of 6-Aza- $B$-homocholest-3,7-dione (11)}

White solid, yield: $80 \% . \mathrm{mp} 238-240{ }^{\circ} \mathrm{C}$. IR (KBr) v: 3346, 2966, 2864, 1723, 1658, $1458 \mathrm{~cm}^{-1} ;{ }^{1} \mathrm{H}$ NMR $\left(\mathrm{CDCl}_{3}, 300 \mathrm{MHz}\right) \delta: 0.72\left(3 \mathrm{H}, \mathrm{s}, 18-\mathrm{CH}_{3}\right), 0.88\left(6 \mathrm{H}, \mathrm{d}, J=6.6,26\right.$ and $\left.27-\mathrm{CH}_{3}\right), 0.91(3 \mathrm{H}, \mathrm{d}$, $\left.J=6.6,21-\mathrm{CH}_{3}\right), 1.07\left(3 \mathrm{H}, \mathrm{s}, 19-\mathrm{CH}_{3}\right), 2.52-2.22\left(6 \mathrm{H}, \mathrm{m}, \mathrm{C}_{2^{-}}, \mathrm{C}_{4^{-}}\right.$and $\left.\mathrm{C}_{7 \mathrm{a}}-\mathrm{H}\right), 3.78-3.66(1 \mathrm{H}, \mathrm{m}$, $\left.\mathrm{C}_{5}-\mathrm{H}\right), 6.10(1 \mathrm{H}, \mathrm{s}, \mathrm{N}-\mathrm{H}) ;{ }^{13} \mathrm{C} \mathrm{NMR}\left(\mathrm{CDCl}_{3}, 75 \mathrm{MHz}\right) \delta: 207.8$ (3-C), 176.4 (7-C), 58.5 (14-C), 58.0 (17-C), 56.5 (9-C), 55.7 (5-C), 43.7 (13-C ), 42.5 (7a-C), 40.2 (4-C), 39.9 (12-C), 39.5 (24-C), 39.0 (10-C), 36.8 (2-C), 36.0 (20-C), 35.9 (22-C), 35.7 (1-C), 34.7 (8-C), 28.0 (16-C), 27.6 (25-C), 25.6 
(23-C), 23.8 (15-C), 23.6 (11-C), 22.8 (27-C), 22.5 (26-C), 18.6 (21-C), 12.2 (19-C), 11.8 (18-C); HRESI-MS $(m / z): 416.3523[\mathrm{M}+\mathrm{H}]^{+}$(calcd for $\mathrm{C}_{27} \mathrm{H}_{46} \mathrm{NO}_{2}$, 416.3529) (Supplementary Information: Figure S7).

\subsubsection{The Synthesis of 3-Hydroximino-6-aza- $B$-homocholest-7-one (12)}

White solid, yield: $85 \%$, mp $248-249{ }^{\circ} \mathrm{C}$. IR (KBr) v: 3235, 2945, 1650, 1458, 1433, 1380, 1119 , $972 \mathrm{~cm}^{-1} ;{ }^{1} \mathrm{H} \mathrm{NMR}\left(\mathrm{CDCl}_{3}, 300 \mathrm{MHz}\right) \delta: 0.70\left(3 \mathrm{H}, \mathrm{s}, 18-\mathrm{CH}_{3}\right), 0.84\left(3 \mathrm{H}, \mathrm{s}, 19-\mathrm{CH}_{3}\right), 0.85(3 \mathrm{H}, \mathrm{d}$, $J=6.6,26$ or $\left.27-\mathrm{CH}_{3}\right), 0.86\left(3 \mathrm{H}, \mathrm{d}, J=6.6,26\right.$ or $\left.27-\mathrm{CH}_{3}\right), 0.94\left(3 \mathrm{H}, \mathrm{d}, J=6.6,21-\mathrm{CH}_{3}\right), 3.58-3.44$ $\left(1 \mathrm{H}, \mathrm{m}, \mathrm{C}_{5}-\mathrm{H}\right), 6.19(1 \mathrm{H}, \mathrm{s}, \mathrm{N}-\mathrm{H}) ;{ }^{13} \mathrm{C} \mathrm{NMR}\left(\mathrm{CDCl}_{3}, 75 \mathrm{MHz}\right) \delta: 176.9$ (7-C), 157.5 (3-C), 58.4 (14-C), 57.4 (17-C), 56.5 (5-C), 55.7 (9-C), 42.5 (7a-C), 40.1 (13-C), 39.9 (10-C), 39.5 (12-C), 37.0 (24-C), 36.0 (22-C), 35.7 (20-C), 34.6 (8-C), 29.6 (4-C), 28.0 (16-C), 27.6 (25-C), 27.0 (2-C), 25.6 (1-C), 23.8 (23-C), 23.2 (15-C), 22.8 (26-C), 22.6 (27-C), 22.1 (11-C), 18.6 (21-C), 12.0 (19-C), 11.8 (18-C); HRESI-MS $(m / z): 431.3630[\mathrm{M}+\mathrm{H}]^{+}$(calcd for $\mathrm{C}_{27} \mathrm{H}_{47} \mathrm{~N}_{2} \mathrm{O}_{2}, 431.3638$ ).

\subsubsection{The Synthesis of 3-O-Methyloximino-6-aza- $B$-homocholest-7-one (13)}

Compounds 13 and 14 were prepared similarly according to the procedure of 11, but $\mathrm{CH}_{3} \mathrm{ONH}_{2} \cdot \mathrm{HCl}$ and $\mathrm{PhCH}_{2} \mathrm{ONH}_{2} \cdot \mathrm{HCl}$ were used as reagents instead of $\mathrm{NH}_{2} \mathrm{OH} \cdot \mathrm{HCl}$.

Compound 13 was a mixture of $(E)$ and $(Z)-13$ (ratio: $E: Z=0.9: 1.1$ ). Yield: $68 \%, \mathrm{mp} 204-205{ }^{\circ} \mathrm{C}$. IR (KBr) v: 3425, 3222, 1954, 2869, 1673, 1048, $1016 \mathrm{~cm}^{-1} ;{ }^{1} \mathrm{H} \mathrm{NMR}\left(\mathrm{CDCl}_{3}, 300 \mathrm{MHz}\right) \delta: 0.66(3 \mathrm{H}$, s, $\left.18-\mathrm{CH}_{3}\right), 0.83\left(3 \mathrm{H}, \mathrm{d}, J=6.6,26-\mathrm{CH}_{3}\right.$ or $\left.27-\mathrm{CH}_{3}\right), 0.84\left(3 \mathrm{H}, \mathrm{d}, J=6.6,26-\mathrm{CH}_{3}\right.$ or $\left.27-\mathrm{CH}_{3}\right), 0.86$ $\left(3 \mathrm{H}, \mathrm{d}, J=6.6,21-\mathrm{CH}_{3}\right), 0.91\left(3 \mathrm{H}, \mathrm{s}, 19-\mathrm{CH}_{3}\right), 3.50-3.38\left(1 \mathrm{H}, \mathrm{m}, \mathrm{C}_{5}-\mathrm{H}\right), 3.01(\mathrm{Z}: 0.55 \mathrm{H}$, br d, $J=14.7$, $\left.\mathrm{C}_{4}-\mathrm{H}\right), 3.31\left(E: 0.45 \mathrm{H}\right.$, ddd, $\left.J=14.4,5.4,1.5, \mathrm{C}_{2}-\beta \mathrm{H}\right), 3.786\left(Z: 3 \mathrm{H}, \mathrm{s},-\mathrm{OCH}_{3}\right), 3.789(E: 3 \mathrm{H}, \mathrm{s}$, $\left.-\mathrm{OCH}_{3}\right), 6.17\left(\mathrm{Z}: 0.55 \mathrm{H}\right.$, br s, N-H), $6.23\left(0.45 \mathrm{H}\right.$, br s, N-H); ${ }^{13} \mathrm{C} \mathrm{NMR}\left(\mathrm{CDCl}_{3}, 75 \mathrm{MHz}\right) \delta: 176.6$ (7-C), 157.0 (3-C, E-), 156.3 (3-C, Z-), $61.2\left(-\mathrm{OCH}_{3}\right), 58.6$ (5-C, Z-), 58.4 (14-C), 57.4 (5-C, E-), 56.4 (17-C), 55.6 (9-C), 42.4 (7a-C), 40.2 (13-C), 40.1 (10-C), 39.9 (12-C), 39.4 (24-C), 37.2 (22-C), 36.2 (20-C), 35.9 (4-C, Z-), 35.7(4-C, E-), 34.7 (8-C, Z-), 34.3 (8-C, E-), 28.0 (16-C), 27.7 (2-C, E-), 27.6 (25-C), 27.1 (2-C, Z-), 25.6 (1-C), 23.7 (23-C), 23.1 (15-C), 22.8 (27-C), 22.6 (26-C), 20.8 (11-C), 18.6 (21-C, E-), 12.1 (19-C, Z-), 12.0 (19-C), 11.8 (18-C); HRESI-MS ( $m / z): 445.3788[\mathrm{M}+\mathrm{H}]^{+}$ (calcd for $\mathrm{C}_{28} \mathrm{H}_{49} \mathrm{~N}_{2} \mathrm{O}_{2}, 445.3794$ ) (Supplementary Information: Figure S8).

\subsubsection{The Synthesis of 3-O-Benzyloximino-6-aza- $B$-homocholest-7-one (14)}

Compound 14 was a mixture of $(E)$ and $(Z)-14$ (ratio: $E: Z=0.9: 1.1$ ). Yield: $63 \%, \mathrm{mp} 195-196{ }^{\circ} \mathrm{C}$. IR(KBr) v : 3424, 3224, 3088, 3031, 2950, 2868, 1672, 1452, 1366, 1351, 1048, 1015, 734, $697 \mathrm{~cm}^{-1}$; ${ }^{1} \mathrm{H}$ NMR $\left(\mathrm{CDCl}_{3}, 300 \mathrm{MHz}\right) \delta: 0.68\left(3 \mathrm{H}, \mathrm{s}, 18-\mathrm{CH}_{3}\right), 0.858\left(3 \mathrm{H}, \mathrm{d}, J=6.6,26-\mathrm{CH}_{3}\right.$ or $\left.27-\mathrm{CH}_{3}\right), 0.863$ $\left(3 \mathrm{H}, \mathrm{d}, J=6.6,26-\mathrm{CH}_{3}\right.$ or $\left.27-\mathrm{CH}_{3}\right), 0.89\left(3 \mathrm{H}, \mathrm{d}, J=6.6,21-\mathrm{CH}_{3}\right), 0.93\left(3 \mathrm{H}, \mathrm{s}, 19-\mathrm{CH}_{3}\right), 3.13(0.5 \mathrm{H}, \mathrm{br}$ $\left.\mathrm{d}, J=15.0, \mathrm{C}_{4}-\mathrm{H}, E-\right), 3.42-3.36\left(0.5 \mathrm{H}, \mathrm{m}, \mathrm{C}_{2}-\mathrm{H}, Z-\right), 3.52-3.42\left(1 \mathrm{H}, \mathrm{m}, \mathrm{C}_{5}-\mathrm{H}\right), 5.05\left(2 \mathrm{H}, \mathrm{s},-\mathrm{OCH}_{2} \mathrm{Ph}\right)$, $5.90(1 \mathrm{H}, \mathrm{s}, \mathrm{N}-\mathrm{H}), 7.36-7.30\left(5 \mathrm{H}, \mathrm{m},-\mathrm{C}_{6} \mathrm{H}_{5}\right) ;{ }^{13} \mathrm{C} \mathrm{NMR}\left(\mathrm{CDCl}_{3}, 75 \mathrm{MHz}\right): 176.4$ (7-C), 157.6 (E: 3-C), 156.9 (Z: 3-C), [Z: 137.9, 128.4, 128.4, 128.1, 128.1, 127.8, $\left.\left(-\mathrm{C}_{6} \mathrm{H}_{5}\right)\right]$, [E: 137.7, 128.4, 128.4, 128.0, 128.0, 127.7, $\left(-\mathrm{C}_{6} \mathrm{H}_{5}\right)$ ], $75.5\left(-\mathrm{OCH}_{2} \mathrm{Ph}\right), 58.5$ (Z: 5-C), 58.3 (14-C), 57.4 (E: 5-C), 56.4 (17-C), 55.7 (9-C), 42.5 (7a-C), 42.4 (13-C), 39.9 (10-C), 39.5 (12-C), 37.2 (24-C), 36.2 (22-C), 35.9 (20-C), 35.7 
(8-C), 34.7 (Z: 4-C), 34.4 (E: 4-C), 28.0 (16-C), 28.0 (25-C), 27.6 (E: 2-C), 27.1 (Z: 2-C), 25.6 (1-C), 23.8 (22-C), 23.1 (15-C), 22.8 (26-C), 22.6 (27-C), 21.1 (11-C), 18.6 (21-C), 12.1 (E: 19-C), 12.0 (Z: 19-C), 11.8 (18-C); HRESI-MS $(m / z): 521.4102[\mathrm{M}+\mathrm{H}]^{+}$(calcd for $\mathrm{C}_{34} \mathrm{H}_{53} \mathrm{~N}_{2} \mathrm{O}_{2}, 521.4107$ ) (Supplementary Information: Figure S9).

\subsubsection{The Synthesis of 6-Aza-7-oxo- $B$-homocholest-3-thiosemicarbazone (15)}

A mixture of compound 11 (100 mg, $0.24 \mathrm{mmol})$, thiosemicarbazide ( $24 \mathrm{mg}, 0.26 \mathrm{mmol}$ ), and a few drops of glacial acetic acid $(0.5 \mathrm{~mL})$ in $95 \%$ ethanol $(20 \mathrm{~mL})$ was stirred at $60-70{ }^{\circ} \mathrm{C}$ for $10 \mathrm{~h}$. After completion of the reaction, the majority of solvent was evaporated and some water was added to this solution. The mixture was extracted with $\mathrm{CH}_{2} \mathrm{Cl}_{2}$ and the extract was washed with saturated brine, dried with anhydrous sodium sulfate and evaporated under reduce pressure. The resulting residue was chromatographed on a column of silica gel with a mixture of DCM-methanol (20:1) to give $80 \mathrm{mg}$ of compound 15. Yield: $70 \%, \mathrm{mp} 274-276{ }^{\circ} \mathrm{C}$. Compound 15 was a mixture of $(E)$ - and $(Z)-\mathbf{1 5}$ (ratio: $E: Z=1: 1)$. IR (KBr) v: 3424, 3237, 2951, 2668, 1658, 1595, 1467, 1386, 1284, 1134, $1078 \mathrm{~cm}^{-1} ;{ }^{1} \mathrm{H}$ NMR (DMSO, $600 \mathrm{MHz}) \delta: 0.64\left(3 \mathrm{H}, \mathrm{s}, 18-\mathrm{CH}_{3}\right), 0.814\left(3 \mathrm{H}, \mathrm{d}, J=6.6,26\right.$ or $\left.27-\mathrm{CH}_{3}\right), 0.818(3 \mathrm{H}, \mathrm{d}$, $J=6.6,26$ or $\left.27-\mathrm{CH}_{3}\right), 0.84\left(1.5 \mathrm{H}, \mathrm{s}, 19-\mathrm{CH}_{3}\right), 0.85\left(1.5 \mathrm{H}, \mathrm{s}, 19-\mathrm{CH}_{3}\right), 0.92\left(3 \mathrm{H}, \mathrm{d}, J=6.0,21-\mathrm{CH}_{3}\right)$, $2.69\left(0.5 \mathrm{H}, \mathrm{d}, J=12.6, \mathrm{C}_{2}-\mathrm{H}, E-\right), 2.81\left(1 \mathrm{H}, \mathrm{br} \mathrm{s}, \mathrm{C}_{4}-\mathrm{H}, Z-\right), 2.97\left(0.5 \mathrm{H}, \mathrm{d}, J=10.8, \mathrm{C}_{4}-\mathrm{H}, Z-\right), 3.51$ $\left(0.5 \mathrm{H}, J=4.8, \mathrm{C}_{5}-\mathrm{H}, E-\right), 3.57\left(0.5 \mathrm{H}, J=4.8, \mathrm{C}_{5}-\mathrm{H}, Z-\right), 7.13\left(1 \mathrm{H}\right.$, br s, $\left.-\mathrm{NH}_{2}\right), 7.29(0.5 \mathrm{H}$, br s, CON-H-), $7.36\left(1 \mathrm{H}\right.$, br s, -NH $\mathrm{NH}_{2}, 7.43(0.5 \mathrm{H}$, br s, CON-H- $), 9.57(0.5 \mathrm{H}$, br s, -NH-, E- $), 10.20(0.5 \mathrm{H}$, br s, -NH-, Z-); ${ }^{13} \mathrm{C}$ NMR (DMSO, $\left.150 \mathrm{MHz}\right) \delta: 178.5$ (C=S), 177.4 (7-C, Z-), 177.1 (7-C, E-), 156.3 (3-C, Z-), 155.1 (3-C, E-), 59.0 (5-C, Z-), 58.3 (5-C, E-), 58.2 (14-C), 56.5 (17-C), 55.6 (9-C), 42.6 (7a-C), 40.3 (10-C, Z-), 40.2 (10-C, E-), 39.9 (13-C), 39.6 (12-C), 39.4 (24-C), 37.7 (4-C, Z-), 37.2 (4-C, E-), 36.2 (2-C, E-), 36.0 (22-C), 35.8 (20-C), 34.7 (8-C), 30.6 (2-C, Z-), 28.1 (16-C), 27.7 (1-C), 25.8 (25-C), 23.9 (23-C), 23.4 (15-C), 23.3 (11-C), 22.7 (27-C), 22.9 (26-C), 18.7 (21-C), 12.6 (19-C, Z-), 12.4 (19-C, E-), 12.0 (18-C); HRESI-MS $(\mathrm{m} / \mathrm{z}): 489.3620\left[\mathrm{M}+\mathrm{H}^{+}\right.$(calcd for $\mathrm{C}_{28} \mathrm{H}_{49} \mathrm{~N}_{4} \mathrm{OS}$, 489.3627) (Supplementary Information: Figure $\mathrm{S} 10$ ).

Compounds in Scheme 3 were prepared similarly according to the procedure of Scheme 1.

\subsubsection{3-Acetoxy-7a-aza- $B$-homocholest-5-ene-7-one (17)}

Yellow solid, yield: 72\%, mp192-194 ${ }^{\circ} \mathrm{C}$. IR (KBr) v: 3424, 2942, 2868, 1740, 1659, 1617, 1442 $\mathrm{cm}^{-1} ;{ }^{1} \mathrm{H}$ NMR $\left(300 \mathrm{MHz}, \mathrm{CDCl}_{3}\right) \delta: 0.69\left(3 \mathrm{H}, \mathrm{s}, 18-\mathrm{CH}_{3}\right), 0.869\left(3 \mathrm{H}, \mathrm{d}, J=6.6,26\right.$ or $\left.27-\mathrm{CH}_{3}\right), 0.874$ $\left(3 \mathrm{H}, \mathrm{s}, J=6.6,26\right.$ or $\left.27-\mathrm{CH}_{3}\right), 0.92\left(3 \mathrm{H}, \mathrm{d}, J=6.6,21-\mathrm{CH}_{3}\right), 1.27\left(3 \mathrm{H}, \mathrm{s}, 19-\mathrm{CH}_{3}\right), 2.05(3 \mathrm{H}, \mathrm{s}$, $\left.2^{\prime}-\mathrm{CH}_{3}\right), 2.46\left(1 \mathrm{H}, \mathrm{dd}, J=13.2,3.6, \mathrm{C}_{4}-\beta \mathrm{H}\right), 2.61\left(1 \mathrm{H}, \mathrm{t}, J=11.7, \mathrm{C}_{4}-\alpha \mathrm{H}\right), 3.29\left(1 \mathrm{H}, \mathrm{t}, J=8.4, \mathrm{C}_{8}-\mathrm{H}\right)$, 4.76-4.65 (1H, m, C $\left.\mathrm{C}_{3}-\alpha \mathrm{H}\right), 5.66(1 \mathrm{H}$, br s, $-\mathrm{NH}-), 5.83\left(1 \mathrm{H}, \mathrm{s}, \mathrm{C}_{6}-\mathrm{H}\right) ;{ }^{13} \mathrm{C}$ NMR $\left(75 \mathrm{MHz}, \mathrm{CDCl}_{3}\right) \delta$ : 170.3 (1'-C), 167.4 (7-C), 156.1 (5-C), 122.5 (6-C), 72.5 (3-C), 55.7 (14-C), 55.4 (17-C), 51.7 (8-C), 48.9 (9-C), 43.8 (24-C), 41.8 (12-C), 41.6 (13-C), 39.4 (15-C), 38.6 (10-C), 35.9 (4-C), 35.5 (1-C), 35.4 (22-C), 28.0 (20-C), 27.8 (25-C), 27.0 (2-C), 25.1 (16-C), 23.8 (23-C), 23.2 (11-C), 22.8 (26-C), 22.5 (27-C), 21.3 (2'-C), 19.3 (21-C), 18.6 (19-C), 11.4 (18-C); HRESI-MS (m/z): 458.3623 [M + H] (calcd for $\mathrm{C}_{29} \mathrm{H}_{48} \mathrm{NO}_{3}, 458.3634$ ) (Supplementary Information: Figure $\mathrm{S} 11$ ). 


\subsubsection{3-Hydroxy-7a-aza- $B$-homocholest-5-ene-7-one (18)}

Yellow solid, yield: $74.5 \%, \mathrm{mp} 207-209^{\circ} \mathrm{C}$; IR (KBr) v: 3383, 2946, 2860, 1663, 1601, $1438 \mathrm{~cm}^{-1}$; ${ }^{1} \mathrm{H}$ NMR $\left(300 \mathrm{MHz}, \mathrm{CDCl}_{3}\right) \delta: 0.65\left(3 \mathrm{H}, \mathrm{s}, 18-\mathrm{CH}_{3}\right), 0.837\left(3 \mathrm{H}, \mathrm{d}, J=6.6,26\right.$ or $\left.27-\mathrm{CH}_{3}\right), 0.842(3 \mathrm{H}$, $\mathrm{s}, J=6.6,26$ or $\left.27-\mathrm{CH}_{3}\right), 0.89\left(3 \mathrm{H}, \mathrm{d}, J=6.6,21-\mathrm{CH}_{3}\right), 1.24\left(3 \mathrm{H}, \mathrm{s}, 19-\mathrm{CH}_{3}\right), 2.40(1 \mathrm{H}, \mathrm{dd}, J=13.2$, $\left.3.3, \mathrm{C}_{4}-\beta \mathrm{H}\right), 2.53\left(1 \mathrm{H}, \mathrm{t}, J=11.7,3.6, \mathrm{C}_{4}-\alpha \mathrm{H}\right), 3.25\left(1 \mathrm{H}, \mathrm{t}, J=8.1, \mathrm{C}_{8}-\mathrm{H}\right), 3.65-3.54\left(1 \mathrm{H}, \mathrm{m}, \mathrm{C}_{3}-\alpha \mathrm{H}\right)$, $5.77\left(1 \mathrm{H}, \mathrm{s}, \mathrm{C}_{6}-\mathrm{H}\right), 6.01(1 \mathrm{H}$, br s, $-\mathrm{NH}-) ;{ }^{13} \mathrm{C} \mathrm{NMR}\left(75 \mathrm{MHz}, \mathrm{CDCl}_{3}\right) \delta: 168.2(7-\mathrm{C}), 158.6(5-\mathrm{C})$, 121.0 (6-C), 70.6 (3-C), 55.6 (14-C), 55.1 (17-C), 51.6 (8-C), 49.1 (9-C), 46.3 (13-C), 44.2 (4-C), 41.7 (24-C), 39.4 (12-C), 38.5 (15-C), 36.0 (1-C), 35.9 (22-C), 35.5 (20-C), 30.5 (10-C), 28.0 (2-C), 27.8 (25-C), 25.1 (16-C), 23.8 (23-C), 23.1 (11-C), 22.8 (26-C), 22.5 (27-C), 19.4 (21-C), 18.6 (19-C), 11.3 (18-C); HRESI-MS $(\mathrm{m} / \mathrm{z})$ : $416.3515[\mathrm{M}+\mathrm{H}]^{+}$(calcd for $\mathrm{C}_{27} \mathrm{H}_{46} \mathrm{NO}_{2}, 416.3529$ ) (Supplementary Information: Figure S12).

\subsubsection{7a-Aza- $B$-homocholest-4-ene-3,7-dione (19)}

Faint yellow solid, yield: 43.0\%, mp $203-205{ }^{\circ} \mathrm{C}$; IR (KBr) v: 3367, 2958, 2860, 1675, $1462 \mathrm{~cm}^{-1}$; ${ }^{1} \mathrm{H}$ NMR $\left(300 \mathrm{MHz}, \mathrm{CDCl}_{3}\right) \delta: 0.72\left(3 \mathrm{H}, \mathrm{s}, 18-\mathrm{CH}_{3}\right), 0.845\left(3 \mathrm{H}, \mathrm{d}, J=6.6,26\right.$ or $\left.27-\mathrm{CH}_{3}\right), 0.850(3 \mathrm{H}$, $\mathrm{s}, J=6.6,26$ or $\left.27-\mathrm{CH}_{3}\right), 0.90\left(3 \mathrm{H}, \mathrm{d}, J=6.6,21-\mathrm{CH}_{3}\right), 1.27\left(3 \mathrm{H}, \mathrm{s}, 19-\mathrm{CH}_{3}\right), 2.37-2.28(2 \mathrm{H}, \mathrm{m}$, $\left.\mathrm{C}_{2}-\mathrm{H}\right), 2.94\left(1 \mathrm{H}, \mathrm{d}, J=12.6, \mathrm{C}_{6}-\beta \mathrm{H}\right), 3.55\left(1 \mathrm{H}, \mathrm{d}, J=12.6, \mathrm{C}_{6}-\alpha \mathrm{H}\right), 3.52-3.46\left(1 \mathrm{H}, \mathrm{m}, \mathrm{C}_{8}-\mathrm{H}\right), 5.82$ (1H, br s, -CONH-), $5.93\left(1 \mathrm{H}, \mathrm{s}, \mathrm{C}_{4}-\mathrm{H}\right) ;{ }^{13} \mathrm{C} \mathrm{NMR}\left(75 \mathrm{MHz}, \mathrm{CDCl}_{3}\right.$ ) $\delta: 198.4$ (3-C), 172.5 (7-C), 162.8 (5-C), 126.9 (4-C), 55.8 (17-C), 54.0 (14-C), 52.4 (8-C), 49.2 (9-C), 42.7 (6-C), 41.6 (13-C), 41.3 (24-C), 39.4 (12-C), 38.2 (10-C), 35.9 (15-C), 35.5 (1-C), 34.1 (22-C), 33.4 (20-C), 28.0 (2-C), 27.9 (25-C), 27.7 (16-C), 24.8 (23-C), 23.8 (11-C), 22.8 (26-C), 22.6 (27-C), 21.2 (21-C), 18.6 (19-C), 11.7 (18-C); HRESI-MS (m/z): $414.3362[\mathrm{M}+\mathrm{H}]^{+}$(calcd for $\mathrm{C}_{28} \mathrm{H}_{47} \mathrm{~N}_{4} \mathrm{OS}$, 414.3372) (Supplementary Information: Figure S13).

\subsubsection{3-Hydroximino-7a-aza- $B$-homocholest-4-ene-7-one (20)}

Faint yellow solid, yield: $77.3 \%, \mathrm{mp} 204-206^{\circ} \mathrm{C}$. IR (KBr) v: 3268, 2949, 2868, 1658, 1657, 1462, $1366 \mathrm{~cm}^{-1} ;{ }^{1} \mathrm{H} \mathrm{NMR}\left(\mathrm{CDCl}_{3}, 300 \mathrm{MHz}\right) \delta: 0.73\left(3 \mathrm{H}, \mathrm{s}, 18-\mathrm{CH}_{3}\right), 0.88\left(6 \mathrm{H}, \mathrm{d}, J=6.6,26-\right.$ and $\left.27-\mathrm{CH}_{3}\right)$, $0.93\left(3 \mathrm{H}, \mathrm{d}, J=6.6,21-\mathrm{CH}_{3}\right), 1.22\left(3 \mathrm{H}, \mathrm{s}, 19-\mathrm{CH}_{3}\right), 2.33-2.22\left(2 \mathrm{H}, \mathrm{m}, \mathrm{C}_{2}-\mathrm{H}\right), 2.79(1 \mathrm{H}, \mathrm{br} \mathrm{d}, J=17.4$, $\left.\mathrm{C}_{2}-\mathrm{H}\right), 2.94\left(1 \mathrm{H}, \mathrm{d}, J=13.5, \mathrm{C}_{6}-\beta \mathrm{H}\right), 3.47\left(1 \mathrm{H}, \mathrm{d}, J=13.5, \mathrm{C}_{6}-\alpha \mathrm{H}\right), 3.52-3.45\left(1 \mathrm{H}, \mathrm{m}, \mathrm{C}_{8}-\mathrm{H}\right), 5.77$

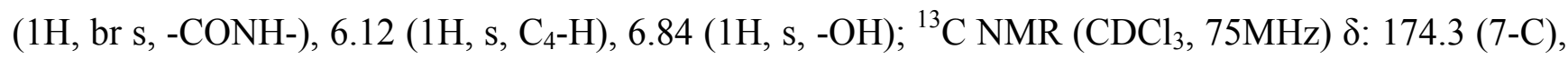
156.1 (3-C), 147.5 (5-C), 121.8 (4-C), 55.9 (14-C), 54.4 (17-C), 52.5 (8-C), 50.0 (13-C), 49.1 (9-C), 42.8 (6-C), 41.0 (24-C), 40.6 (10-C), 39.4 (12-C), 38.5 (15-C), 35.9 (22-C), 35.5 (20-C), 33.0 (1-C), 29.7 (25-C), 28.0 (2-C), 27.7 (16-C), 24.9 (23-C), 23.8 (11-C), 22.8 (26-C), 22.5 (27-C), 21.0 (19-C), 18.6 (21-C), 11.7 (18-C); HRESI-MS (m/z): $429.3463[\mathrm{M}+\mathrm{H}]^{+}$(calcd for $\mathrm{C}_{27} \mathrm{H}_{45} \mathrm{~N}_{2} \mathrm{O}_{2}, 429.3481$ ).

\subsubsection{7-Oxo-7a-aza- $B$-homocholest-4-ene-3-thiosemicarbazone (21)}

Faint yellow solid, yield: $31 \%, \mathrm{mp} 230-231{ }^{\circ} \mathrm{C}$; $\operatorname{IR}(\mathrm{KBr})$ v: 3436, 2954, 2856, 1659, 1573, $1409 \mathrm{~cm}^{-1} ;{ }^{1} \mathrm{H}$ NMR $\left(\mathrm{CDCl}_{3}, 300 \mathrm{MHz}\right) \delta: 0.75\left(3 \mathrm{H}, \mathrm{s}, 18-\mathrm{CH}_{3}\right), 0.88\left(3 \mathrm{H}, \mathrm{d}, J=6.6,26\right.$ or $\left.27-\mathrm{CH}_{3}\right)$, $0.89\left(3 \mathrm{H}, \mathrm{d}, J=6.6,26\right.$ or $\left.27-\mathrm{CH}_{3}\right), 0.94\left(3 \mathrm{H}, \mathrm{d}, J=6.3,21-\mathrm{CH}_{3}\right), 1.26\left(3 \mathrm{H}, \mathrm{s}, 19-\mathrm{CH}_{3}\right), 2.97(1 \mathrm{H}, \mathrm{d}$, $\left.J=13.2, \mathrm{C}_{6}-\beta \mathrm{H}\right), 3.51\left(1 \mathrm{H}, \mathrm{d}, J=13.2, \mathrm{C}_{6}-\alpha \mathrm{H}\right), 3.56-3.48\left(1 \mathrm{H}, \mathrm{m}, \mathrm{C}_{8}-\mathrm{H}\right), 5.28(1 \mathrm{H}$, br s, $-\mathrm{CONH}-)$, 
$6.10\left(1 \mathrm{H}, \mathrm{s}, \mathrm{C}_{4}-\mathrm{H}\right), 6.37\left(1 \mathrm{H}\right.$, br s, $\left.-\mathrm{NH}_{2}\right), 7.25\left(1 \mathrm{H}\right.$, br s, $\left.-\mathrm{NH}_{2}\right), 8.64(1 \mathrm{H}, \mathrm{s},-\mathrm{NH}-\mathrm{CS}) ;{ }^{13} \mathrm{C} \mathrm{NMR}$ $\left(\mathrm{CDCl}_{3}, 75 \mathrm{MHz}\right) \delta: 178.7(\mathrm{C}=\mathrm{S}), 173.6$ (7-C), 150.5 (5-C), 148.9 (3-C), 124.2 (4-C), 55.9 (14-C), 54.3 (17-C), 52.5 (8-C), 49.2 (9-C), 42.8 (6-C), 41.1 (13-C), 40.5 (24-C), 39.4 (12-C), 38.4 (15-C), 35.9 (22-C), 35.5 (20-C), 32.8 (10-C), 29.7 (1-C), 28.0 (25-C), 24.9 (16-C), 23.8 (23-C), 22.8 (26-C), 22.5 (27-C), 22.4 (2-C), 21.0 (11-C), 20.0 (21-C), 18.6 (19-C), 11.7 (18-C); HRESI-MS (m/z): 487.3491 $[\mathrm{M}+\mathrm{H}]^{+}$(calcd for $\mathrm{C}_{28} \mathrm{H}_{47} \mathrm{~N}_{4} \mathrm{OS}, 487.3471$ ) (Supplementary Information: Figure S14).

\subsection{Biology}

\subsubsection{Assay for Cell Viability}

The cell proliferation assay was undertaken by a MTT method using 96-well plates on a MLLTISKAN MK3 analysis spectrometer. GNE 2 (nasopharyngeal carcinoma), SPC-A (lung carcinoma) and Tu 686 (laryngic carcinoma) cell lines were obtained by Guangxi Medical University (Guangxi, China); MGC 7901 (human gastric carcinoma) and HeLa (human cervical carcinoma) cell lines were obtained by Guangxi Traditional Chinese Medical University. Cells were grown in RPMI-1640 supplemented with 10\% cosmic calf serum (Hyclone) and antibiotics in a humidified atmosphere of $5 \% \mathrm{CO}_{2}$ at $37{ }^{\circ} \mathrm{C}$. The viability of these cells was determined using the colorimetric CellTiter 96 aqueous Cell Proliferation Assay (MTT) according to the instruction provided by the manufacturer (Promega, Madison, WI, USA). Briefly, cells (1-3 × $10^{4}$ cells per well) were seeded in 96 wells plates. One day after seeding, the cells were treated with or without different concentration of each compound and reincubated for $72 \mathrm{~h}$. After the cells were washed with sterile phosphate buffer saline (PBS), $190 \mu \mathrm{L}$ of RPMI-1640 and $10 \mu \mathrm{L}$ of the tetrazolium dye (MTT) $(5 \mathrm{mg} / \mathrm{mL})$ solution were added to each well, and the cells were incubated for an additional $4 \mathrm{~h}$. The medium was discarded; $200 \mu \mathrm{L}$ of DMSO was added to dissolve the purple formazan crystals formed. The absorbance (A) at $492 \mathrm{~nm}$ was measured using a MLLTISKAN MK3 analysis spectrometer. The $\mathrm{IC}_{50}$ value was calculated in $\mu \mathrm{mol} / \mathrm{L}$ in Table 1 as the concentration of drug yielding $50 \%$ cell survival. The effect of compound $\mathbf{5}$ on the morphology of treated human carcinoma cells was investigated by the light microscope and then photographed by TE2000-U Nikon (Tokyo, Honshu, Japan) inverted microscope.

\subsubsection{D Multicellular Spheroids}

H292 (lung adenocarcinoma) cancer cells were obtained from ATCC, Manassas, VA. C. Monolayer cultures were incubated in RPMI-1640 supplemented with $10 \%$ fetal bovine serum, 100 units $/ \mathrm{mL}$ penicillin. The cell cultures were kept at $37{ }^{\circ} \mathrm{C}$ in a humidified $5 \% \mathrm{CO}_{2}$ and $95 \%$ air incubator. Uniform single-spheroid H292 lung carcinoma cells were cultured as follows. The 96-well flat-bottom plates were coated with $70 \mu \mathrm{L}$ of a $1.5 \%$ agarose (weight/volume) solution in distilled water (freshly autoclaved). During the coating process, the agarose solution was maintained at $\geq 60{ }^{\circ} \mathrm{C}$ followed by cooling and setting at room temperature for $40 \mathrm{~min}$. Then the cells were plated at a density of 5000 cells/well in $80 \mu \mathrm{L}$ of RPMI-1640 (10\% FBS), and allowed to form spheroid in $48 \mathrm{~h}$. The spheroids were then treated with $20 \mu \mathrm{L}$ of a $25 \%$ solution of growth factor-reduced Matrigel ${ }^{\mathrm{TM}}$ in cell culture medium, resulting in a final volume of $100 \mu \mathrm{L}$ with $5 \%$ Matrigel. Spheroids were cultured for one more day to reach an average diameter of $100 \mu \mathrm{m}$ under standard tissue culture conditions $\left(37^{\circ} \mathrm{C}, 5 \%\right.$ 
$\mathrm{CO} 2$ ). For drug treatment, $100 \mu \mathrm{L}$ fresh medium with various concentration of drugs were added at day 3 (final matrigel concentration became $2.5 \%$ as well). Spheroid morphological images in 96-well microplate were carried out manually on an inverted microscope equipped with camera. Spheroid diameters and volumes were determined from their images. The treatment was quart replicated, and the spheroid images were taken every other day. The suppression of the spheroid growth was normalized with control treatment $(0.1 \%$ DMSO) $[21,22]$.

\subsubsection{Annexin V Staining Assay}

Apoptosis was detected with an annexin V-FITC kit purchased from BD Pharmingen (San Diego, CA, USA) according to the manufacturer's instructions. SGC-7901 cells were seeded in $35 \mathrm{~mm}$ culture dishes and allowed to attach overnight. The cells were treated with different concentration of compound 5 for $24 \mathrm{~h}$ respectively, collected, and washed twice with PBS. To detect early and late apoptosis, both adherent and floating cells were harvested together and resuspended in annexin $\mathrm{V}$ binding buffer at a concentration of $10^{6}$ cells $/ \mathrm{mL}$. Subsequently, $5 \mu \mathrm{L}$ of FITC-conjugated annexin V and $5 \mu \mathrm{L}$ of propidium iodide were added to $100 \mu \mathrm{L}$ of the cell suspension ( $10^{5}$ cells). The cells were incubated for $15 \mathrm{~min}$ at room temperature in the dark. Finally, $400 \mu \mathrm{L}$ of annexin V binding buffer was added to each tube, and cells were analyzed by a two color cytometry using FACS Calibur (Becton Dickinson, Biosciences, Franklin Lakes, NJ, USA).

\section{Conclusions}

We have prepared a series of aza- $B$-homocholestane derivatives having different substituted groups at 3-postion of the steroidal nucleus, taking analogues of marine steroidal oximes as precursors. The antiproliferative activity of the synthesized compounds against SGC-7901, HeLa, Bel-7404, GNE 2, SPC-A and $\mathrm{Tu} 686$ cell lines was investigated. The results showed that aza- $B$-homocholestane derivatives possessing 3-hydroxyl, 3-hydroximino and 3-thiosemicarbazone groups showed remarkable cytotoxic activity. In the synthesized compounds, compounds 5, 10, 12, 15 and 18 were found to be the most potent compounds as anticancer agents, and they displayed a similar antiproliferative activity as cisplatin did. The result of 3D multicellular spheroids screening of $\mathbf{1 5}$ showed also distinct antiproliferative activity, and Annexin V staining assay indicated that compound $\mathbf{5}$ was able to effectively induce tumor cells apoptosis. Compounds $\mathbf{5}$ and $\mathbf{1 5}$ are now submitted to further acute toxicity and antitumor activity studies in animal models, and the relative possible results will be reported in due course. Our findings provide new evidence showing the relationship between the chemical structure and biological activities, and may be useful for the design of novel chemotherapeutic drugs.

\section{Acknowledgments}

The authors acknowledge the financial support of the Natural Science Foundation of Guangxi Province (No: 2010GXNSFD013019) , Natural Science Fund of Education Department of Guangxi province (No. 201202ZD059) and The Training Project for Excellent Middle-aged/Young Teachers in Guangxi Higher Education Institutions. 


\section{Author Contributions}

J. G. Cui was responsible for the natural science foundation of guangxi province (No: 2010GXNSFD013019), and conceived the design of synthetic route and was responsible for the guidance of all synthetic experiments. Y. H. Huang, C. J. Chen and Q. F. Lin synthetized Aza- $B$-homocholestane derivatives. H. C. Song was responsible for the guidance of partial synthetic experiments. Y. H. Huang screened cell lines in vitro. Y. H. Huang and C. F. Gan performed the apoptotic experiment. B. Su, A. M. Zhou and Y. H. Huang screened the 3D Multicellular Spheroids.

\section{Conflicts of Interest}

The authors declare no conflict of interest.

\section{References}

1. Blunt, J.W.; Copp, B.R.; Munro, M.H.G.; Northcote, P.T.; Prinsep, M.R. Marine natural products. Nat. Prod. Rep. 2011, 28, 196-268.

2. Rodríguez, J.; Nunez, L.; Pexinho, S.; Jiménez, C. Isolation and synthesis of the first natural 6-hydroximino-4-en-3-one steroids from the sponges Cinachyrella spp. Tetrahedron Lett. 1997, $38,1833-1836$.

3. Deive, N.; Rodríguez, J.; Jiménez, C. Synthesis of cytotoxic 6E-hydroximino-4-ene steroids: Structure/activity studies. J. Med. Chem. 2001, 44, 2612-2618.

4. Rega, M.; Jiménez, C.; Rodríguez, J. 6E-Hydroximinosteroid homodimerization by cross-metathesis processes. Steroids 2007, 72, 729-735.

5. Bazin, M.A.; Loiseau, P.M.; Bories, C.; Letourneux, Y.; Rault, S.; Kihel, L.E. Synthesis of oxysterols and nitrogenous sterols with antileishmanial and trypanocidal activities. Eur. J. Med. Chem. 2006, 41, 1109-1116.

6. Poza, J.; Rega, M.; Paz, V.; Alonso, B.; Rodríguez, J.; Salvador, N.; Antonio, F.; Carlos, J. Synthesis and evaluation of new 6-hydroximinosteroid analogs as cytotoxic agents. Bioorg. Med. Chem. 2007, 15, 4722-4740.

7. Cui, J.G.; Fan, L.; Huang, L.L.; Liu, H.L.; Zhou, A.M. Synthesis and evaluation of some steroidal oximes as cytotoxic agents: Structure/activity studies (I). Steroids 2009, 74, 62-72.

8. Cui, J.G.; Fan, L.; Huang, Y.M.; Xin, Y.; Zhou, A.M. Synthesis and evaluation of some steroidal oximes as cytotoxic agents: Structure/Activity Studies (II). Steroids 2009, 74, 989-995.

9. Ibrahim-Ouali, M.; Rocheblave, L. Recent advances in azasteroids chemistry. Steroids 2008, 73, $375-407$.

10. Krstić, N.M.; Bjelaković, M.S.; Žižak, Ž.; Pavlović, M.D.; Juranić, Z.D.; Pavlović, V.D. Synthesis of some steroidal oximes, lactams, thiolactams and their antitumor activities. Steroids 2007, 72, 406-414.

11. Anna, I.K.; Manolis, A.; Evagelia, S.A.; Athanasios, P.; George, N.P.; Sotiris, S.N. Rational design, synthesis, and in vivo evaluation of the antileukemic activity of six new alkylating steroidal esters. Bioorg. Med. Chem. 2008, 16, 5207-5215. 
12. Vatmurge, N.S.; Hazra, B.G.; Pore, V.S.; Synthesis and antimicrobial activity of $\beta$-lactam-bile acid conjugates linked via triazole. Bioorg. Med. Chem. Lett. 2008, 18, 2043-2047.

13. Mohamed, E.F.; Gamal, A.E.; Emad, F.E.; Hanaa, M.R.; Mohamed, A.T. Novel modified steroid derivatives of androstanolone as chemotherapeutic anti-cancer agents. Eur. J. Med. Chem. 2009, 44, 3936-3946.

14. Dhingraa, N.; Bhardwaj, T.R.; Mehta, N.; Mukhopadhyay, T.; Kumar, A.; Kumar, M. Synthesis, antiproliferative, acute toxicity and assessment of antiandrogenic activities of some newly synthesized steroidal lactams. Eur. J. Med. Chem. 2010, 45, 2229-2236.

15. Catsoulacos, P.; Politis, D.; Wampler, G.L. Antitumor activity of homo aza-steroidal ester of [ $p$-bis(2-chloroethyl)amino]phenyl acetic acid and [ $p$-bis(2-chloroethyl)amino]phenyl butyric acid. Cancer Chemother. Pharmacol. 1983, 10, 129-132.

16. Catsoulacos, P.; Catsoulacos, D. Antitumor activity of homo-aza-steroidal esters of $p$-N,N-bis(2-chloroetheryl)amino phenoxy acetic acid. Anticancer Res. 1993, 13, 1203-1208.

17. Huang, Y.M.; Chen, S.J.; Cui, J.G.; Gan, C.F.; Liu, Z.P.; Wei, Y.L.; Song, H.C. Synthesis and cytotoxicity of A-homo-lactam derivatives of cholic acid and 7-deoxycholic acid. Steroids 2011, 76, 690-694.

18. Huang, Y.M.; Cui, J.G.; Chen, S.J.; Gan, C.F.; Zhou, A.M. Synthesis and antiproliferative activity of some steroidal lactams. Steroids 2011, 76, 1346-1350.

19. Huang, Y.M.; Cui, J.G.; Zeng, Q.X.; Zeng, C.; Chen, Q.; Zhou, A.M. 6-hydroximino-4-aza- $A$ homo-cholest-3-one and related analogue as a potent inducer of apoptosis in cancer cells. Steroids 2012, 77, 829-834.

20. Tung, Y.C.; Hsiao, A.Y.; Allen, S.G.; Torisawa, Y.S.; Ho, M.; Takayama, S. High-throughput 3D spheroid culture and drug testing using a 384 hanging drop array. Analyst 2011, 136, 473-478.

21. Yuhas, J.M.; Li, A.P.; Martinez, A.O.; Landman, A.J. A simplified method for production and growth of multicellular tumor spheroids. Cancer Res. 1977, 37, 3639-3643.

22. Lama, R.; Zhang, L.; Naim, J.M.; Williams, J.; Zhou, A.; Su, B. Development, validation and pilot screening of an in vitro multi-cellular three-dimensional cancer spheroid assay for anti-cancer drug testing. Bioorg. Med. Chem. 2013, 21, 922-931.

(C) 2014 by the authors; licensee MDPI, Basel, Switzerland. This article is an open access article distributed under the terms and conditions of the Creative Commons Attribution license (http://creativecommons.org/licenses/by/3.0/). 